\title{
Deciphering Core-Phyllomicrobiome of Rice Genotypes Grown in Contrasting Mountain and Island Agroclimatic Zones: Implications for Microbiome Engineering Against Blast Disease
}

Kuleshwar Prasad Sahu

Indian Agricultural Research Institute

Kumar Aundy ( $\sim$ kumar@iari.res.in )

Indian Agricultural Research Institute https://orcid.org/0000-0002-7401-9885

Sakthivel Krishnan

ICAR Central Agricultural Research Institute

Bhaskar Reddy

Indian Agricultural Research Institute

Mukesh Kumar

Indian Agricultural Research Institute

\section{Asharani Patel}

Indian Agricultural Research Institute

Neelam Sheoran

Indian Agricultural Research Institute

Gopalakrishnan Subbaiyan

Indian Agricultural Research Institute

Prakash Ganesan

IARI: Indian Agricultural Research Institute

Rajeev Rathour

CSK HPKV: Himachal Pradesh Agricultural University

Raj K Gautam

Indian Agricultural Research Institute

\section{Research}

Keywords: Antibiosis, Bacterial Volatiles, Blast, Core-Microbiome, Defense genes, Magnaporthe oryzae, Phyllomicrobiome, Phyllosphere, Rice

Posted Date: February 9th, 2021

DOI: https://doi.org/10.21203/rs.3.rs-173841/v1

License: (c) (7) This work is licensed under a Creative Commons Attribution 4.0 International License. Read Full License 


\section{Abstract}

Background

The fundamental role and contributions of phyllosphere habitat in shaping plant functional ecology are poorly investigated, and often underestimated. Phyllosphere -the harsh and dynamic foliar-photosynthetic-habitat is continuously exposed to vagaries of changing weather events during the entire plant life. With its adapted microbiota, the phyllosphere-niche brings microbial diversity to the plant-holobiont pool and potentially modulates a multitude of plant and agronomic traits. The phyllomicrobiome structure and the consequent ecological functions are vulnerable to a host of biotic (Genotypes) and abiotic-factors (Environment) which is further compounded by agronomic-transactions on domesticated agricultural crops. However, the ecological forces driving the phyllomicrobiome assemblage and functions are among the most under-studied aspects of plant biology. Despite the reports on the occurrence of diverse prokaryotic phyla such as Proteobacteria, Firmicutes, Bacteroides, and Actinobacteria on phyllosphere habitat, the functional characterization leading to their utilization for agricultural sustainability is not yet adequately explored.

Currently, the metagenomic-Next-Generation-Sequencing (mNGS) technique scanning the conserved V3-V4 region of ribosomal RNA gene is a widely adopted strategy for microbiome-investigations. However, the structural and functional validation of mNGS annotations by microbiological methods is not integrated into the microbiome exploration-programs. In the present study, we combined the high throughput mNGS approach with conventional microbiological methods to decipher the core-functional-phyllomicrobiome of contrasting rice genotypes varying in their response to blast disease grown in contrasting agroclimatic zones in India. We, further, scanned the rice phyllosphere by electron microscopy to show the microbial communities on leaf.

Magnaporthe oryzae-the phyllosphere pathogen inciting necrotic lesion on cereal crops is managed by the deployment of 'non-durable' blast resistance genes and 'toxic' fungicidal molecules. Nowadays, there is a growing consensus for devising an alternative strategy for mitigating blast owing to a recent ban on the use of most commonly used fungicidal molecule, tricyclazole. In the present work, we further identified phyllosphere-core-functional microbial groups leading to the proposal of phyllomicrobiome assisted rice blast management strategy. Multi-pronged activities of phyllomicrobiome against Magnaporthe oryzae (antifungal activity), rice innate immunity (defense elicitation), and rice blast disease (disease suppression) have been elaborated for effective management of blast by phyllomicrobiome re-engineering.

Results

Rice phyllomicrobiome of tropical "Island-Zone" displayed marginally more bacterial community diversity than that of temperate 'Mountain-Zone'. Principal coordinate analysis based on Bray Curtis and ANoSIM method indicated nearly converging-phyllomicrobiome profiles on two contrasting rice genotypes grown in the same agroclimatic zone. However, the rice genotype grown in the contrasting Mountain-zone and Island-zone displayed diversephyllomicrobiome profiles indicating a strong influence of environmental factors rather than the genotype on phyllomicrobiome structure and assembly. The predominance of Phyla such as Proteobacteria, Actinobacteria, and Firmicutes was observed on the rice phyllosphere irrespective of the genotypes and environmental conditions. The core-microbiome analysis showed multi-microbiota-core consisting of Acidovorax, Arthrobacter, Bacillus, Clavibacter, Clostridium, Cronobacter, Curtobacterium, Deinococcus, Erwinia, Exiguobacterium, Hymenobacter, Kineococcus, Klebsiella, Methylobacterium, Methylocella, Microbacterium, Nocardioides, Pantoea, Pedobacter, Pseudomonas, Salmonella, Serratia, Sphingomonas and Streptomyces on phyllosphere of rice genotypes grown in contrasting agroclimatic zones. The linear discriminant analysis (LDA) effect size (LEfSe) method revealed ten and two distinct bacterial genera in blast-resistant and -susceptible genotypes, respectively. The analysis further indicated 15 and 16 climate-zone specific bacterial genera for Mountain and Island zone, respectively. SparCC based network analysis of phyllomicrobiome showed hundreds of complex intra-microbial cooperative or competitive interactions on the rice genotypes and agroclimatic zones. Our microbiological validation of mNGS data further confirmed the presence of resident Acinetobacter, Aureimonas, Curtobacterium, Enterobacter, Exiguobacterium, Microbacterium, Pantoea, Pseudomonas, and Sphingomonas on the rice phyllosphere. Strikingly, the two contrasting agroclimatic zones displayed genetically identical bacterial isolates on the phyllosphere that could be attributed to the spatio-temporal transmission of core-phyllomicrobiome, perhaps, aided by rice seeds. A total of 59 distinct bacterial isolates were obtained, identified, and evaluated for their functional attributes on Magnaporthe oryzae and rice plant. The phyllomicrobiome associated core-bacterial communities showed secreted-metabolite and volatile-compound mediated antifungal activity on $M$. oryzae. Upon phyllobacterization (a term coined for spraying of bacterial cells on the phyllosphere), the core bacterial species such as Acinetobacter baumannii, Aureimonas sp., Pantoea ananatis, P. eucrina, and Pseudomonas putida elicited plant defense and contributed significantly to blast disease suppression. Transcriptional analysis by qPCR indicated induction of rice innate immunity associated genes such as OsPR1.1, OsNPR1, OsPDF2.2, OsFMO, OsPAD4, OsCEBiP, and OsCERK1 in phyllobacterized rice seedlings.

\section{Conclusions}

The rice genotypes growing in a particular agroclimatic zone showed a convergent phyllomicrobiome assemblage and composition. Conversely, diverging phyllomicrobiome assembly was observed on rice genotype cultivated in the contrasting agroclimatic zones. Agroclimatic zones and the associated climaticfactors rather than plant-genotypes per se appeared to drive phyllomicrobiome structure and composition on the rice genotypes. Our integrated mNGS method and microbiological validation divulged Acinetobacter, Aureimonas, Curtobacterium, Enterobacter, Exiguobacterium, Microbacterium, Pantoea, Pseudomonas, and Sphingomonas as core phyllomicrobiome of rice. Genetically identical bacterial communities belonging to Pantoea intercepted on the phyllosphere of rice grown in the two contrasting agroclimatic zones are suggestive of spatio-temporal transmission of phyllomicrobiome aided by seed. The core-microbiome mediated phyllobacterization showed potential for blast disease suppression by direct-antibiosis and defense elicitation. The identification of phyllosphere adapted functional core-bacterial communities in our study and their co-occurrence dynamics presents an opportunity to devise novel strategies for rice blast management through phyllomicrobiome reengineering in the future.

\section{Background}


Plant microbiota is believed to have an evolutionary-association with higher plants, and together they function as meta-organism in the environment. The total microbiota colonizing the plants is termed as plant holobiont which, often, gives a functional extension and metabolic flexibility to the plant genomes [1, 2]. Microbial members of the microbiomes interact dynamically among them as well as with the plant species displaying cooperative or competitive relationships. Hence, the intra-microbial interaction is believed to impact not only the composition of the microbiomes but also the physiological and ecological functions of the host plants in general.

The phyllosphere, a subset of the phytosphere, is touted as a harsh plant-associated habitat for diverse microbiota that host phyllomicrobiome. The total global phyllosphere is predicted to represent $10^{9}$ square kilometers that could harbor $10^{26}$ bacterial cells [3]. On the phyllosphere niche, the microbiome is not only affected by biotic and abiotic factors but also by nutrient depletion [4, 5]. Unlike rhizosphere and endophytic microbiome, the phyllomicrobiome is not extensively investigated in many crop plants. However, the prokaryotic microbial association on rice phyllosphere and their complex-interactions modulating plant growth, and protection against microbial pathogens are reported. It is widely perceived that the phyllosphere prokaryotic diversity and their population size are large enough to play a pivotal role in plant growth $[6,7]$ and defense against pathogens $[8,9]$. Microbial interactions with their host plants can also be neutral and commensal [10]. The plant genotype, climate, geographical location, edaphic factors, and agronomic practices are among the key factors shaping the phyllosphere microbiota composition and their ecological functions [3, 11-13]. Although predicted and highlighted in many publications, the key drivers of phyllomicrobiome composition and their functions are not completely understood.

Qualitatively, majority of the microbiota of phyllomicrobiome are non-pathogenic bacteria that belong to a few phyla such as Proteobacteria, Firmicutes,

Bacteroides, and Actinobacteria [14, 15]. At lower taxonomic hierarchy, bacterial genera frequently encountered on phyllosphere are Kineococcus, Hymenobacter,Acinetobacter, Bacillus, Citrobacter, Curtobacterium, Enterobacter, Erwinia, Frigoribacterium, Methylobacterium, Pantoea, Pseudomonas, and Sphingomonas [15-20]. For epiphytic-colonization, microbes have evolved adaptive traits such as dark pigmented cells, extracellular polymeric substances, biosurfactants, biofilms, and utilization of plant/ microbial volatile compounds [21]. Furthermore, the epiphytic bacterial communities presumed to survive on sugar-photosynthates sourced from the leaf interior diffused through the cuticle to the epiphytic surface [22, 23].

The rice phyllosphere is also a habitat for foliar pathogens like Magnaporthe and Xanthomonas that cause leaf-diseases. Blast disease caused by Magnaporthe oryzae (anamorph Pyricularia oryzae Sacc.) remains a global production constraint and a threat to food security in developing nations [24-27]. Blast disease of rice accounts for nearly $30 \%$ production loss, which is enough to feed 60 million world's population if managed preemptively [28]. Currently, blast management depends heavily on fungicides and host-resistance; both are inadequate to combat the production losses during epidemics. While the fungicides are not compatible with the environment and trade, the host plant resistance is non-durable owing to the emergence of new pathotypes [29]. It is, further, reported that the blast resistance conferred by host resistance genes often breaks down within 3-5 years of rice cultivation due to the preexisting virulence diversity of $M$. oryzae [30]. Therefore, there is a need for the development of a sustainable and durable blast management strategy for rice. Bespoke microbiome therapy is proposed as NextGen-Crop-care strategy to ensure eco-friendly crop disease management [31]. Microbial strains with desired functions can be selected and engineered to form synthetic microbiomes for agricultural applications [32]. The perceived advantage is the ability of syntheticmicrobiome to buffer against environmental perturbations. However, the development of such synthetic microbiomes is, often, hampered by our limited understanding of the core functional microbiome. Harnessing the potential of naturally occurring phyllomicrobiome for foliar disease and crop management has not been attempted till date. Since the phyllosphere microbiomes have been reported to play a pivotal role in growth, development, and defense against biotic and abiotic stress, profiling the phyllomicrobiome for deciphering the functions assumes significance.

With this background, the current investigation was conducted to identify the core-phyllomicrobiome of rice and its potential to suppress blast disease. We, further, attempted to decipher the major driver(s) of phyllosphere microbiome composition using the integrated metagenomic Next Generation Sequencing (mNGS) approach and conventional microbiological methods. For this purpose, phyllomicrobiome samples were generated from two contrasting rice genotypes differing for a single resistance-gene, Pi2 conferring complete resistance to blast, thereby varying for their reaction to blast disease, grown in twocontrasting agro-climatic zones in India separated by more than $2800 \mathrm{Km}$. The agroclimatic zones represented Mountain-zone in the Himalayan region (Palampur) and Island-zone in Andaman Island in the Bay-of-Bengal, India (Port Blair). While the mountain-zone in Palampur is an endemic-location for blast disease, the island-zone in Port Blair is non-endemic.

We identified the core-phyllomicrobiome of rice genotypes in the combined and comparative mNGS and microbiological data. The results indicated the association of complex microbial assemblages displaying diverse-functions on the rice phyllosphere for rice blast management. Our in-vitro screening of phyllomicrobiome against M.oryzae and in-planta evaluation trial against rice blast disease further confirmed the potential of functional-microbial groups for phyllomicrobiome assisted rice cultivation in the future.

\section{Methods}

\section{Study location and sampling for phyllomicrobiome assessment}

Metagenomic NGS (mNGS), microbiological and microscopic experiments were performed on rice phyllomicrobiome sampled from the rice plots of two contrasting agroclimatic-zones of India. The experimental sites were, (i). blast-endemic mountain-zone at Palampur, Himachal Pradesh, India [32 $6^{\prime} 4.7^{\prime \prime} N$, 76 32'39.79"E; altitude 1275 meter above mean sea level (MSL); mean temperature 22-23 ${ }^{\circ} \mathrm{C}$; mean rainfall $700-1000$ mm; relative humidity (RH) 60.0\%; sunshine hours 300-350 h]; and (ii). blast non-endemic Island-zone in Port Blair, Andaman Island, India [11 ${ }^{\circ} 38^{\prime} 07.0^{\prime \prime} \mathrm{N}, 92^{\circ} 39^{\prime} 12.7^{\prime \prime} \mathrm{E}$ ); altitude 16 meters above MSL, mean temperature $26-28{ }^{\circ} \mathrm{C}$, mean rainfall $3060 \mathrm{~mm}$; RH $80.0 \%$ (https://en.climate-data.org; (www.worldweatheronline.com)]. Both experiments were conducted during rice cultivation seasons in August - September 2016 at Palampur and March - April 2017 in Port Blair. Blast disease susceptible genotype, PRR 78 and its near-isogenic line Pusa 1602 introgressed with Pi2 gene [33] conferring complete resistance to blast disease were planted and grown in parallel rows with spacing of $20 \mathrm{~cm}$ by adopting standard agronomic practices. Phyllosphere samples were collected aseptically in sterilized falcon-tubes on 
15 and 30 days post sowing. Phyllosphere samples were collected aseptically in sterilized falcon-tubes on 15-and 30-days post sowing. Thus collected samples in two replications were transported to the laboratory in cool-containers maintained at $4{ }^{\circ} \mathrm{C} \pm 0.5^{\circ} \mathrm{C}$, and processed for microbiomes profiling within 48 hours.

\section{mNGS based profiling of phyllomicrobiome}

Extraction of phyllosphere microbial genomic DNA: Leaf $(5.0 \mathrm{~g})$ samples collected from the two rice genotypes in two replications were shaken with 50 ml of sterile phosphate buffer saline [PBS, g L ${ }^{-1} \mathrm{NaCl} 8 ; \mathrm{KCl} 0.2 ; \mathrm{Na}_{2} \mathrm{HPO}_{4} 1.44 ; \mathrm{KH}_{2} \mathrm{PO}_{4} 0.24 ; \mathrm{pH}-7.4$ ] amended with $0.1 \%$ Tween-20 (PBS-T) to dislodge the phyllomicrobiome. Thus, collected phyllosphere samples were serially extracted six times in $50 \mathrm{ml}$ of PBS buffer by vigorous shaking for 30 minutes at 250 $\mathrm{rpm}$ followed by vortexing for $10 \mathrm{~s}$. Thus separated phyllomicrobiome suspension $(300 \mathrm{~mL})$ was collected aseptically in a pre-sterilized container and centrifuged at $12 \mathrm{~K} \mathrm{~g}$ force for $60 \mathrm{~min}$ at $4.0^{\circ} \mathrm{C}$ to collect the phyllomicrobiome pellets. The pellet obtained was subjected to total microbial community DNA extraction by Cetyl Trimethyl Ammonium Bromide (CTAB) method previously described by Moore et al [34]. The quality and yield of microbial community DNA were assessed electrophoretically, spectrophotometrically (Nanodrop 2000, Thermo Scientific, USA), and fluorometrically (Qubit dsDNA BR Assay; Thermo Fisher Scientific Inc., Qubit@ 2.0).

Preparation of mNGS libraries for 2 x $\mathbf{3 0 0}$ bp Sequencing Chemistry: The amplicon-libraries were prepared using Nextera XT Index Kit (Illumina Inc. San Diego, CA, USA) as prescribed for the 16S rRNA gene-sequence based Metagenomic Sequencing Library Preparation Protocol (Part \# 15044223 Rev. B). Primers for the amplification of the 490 -bp hyper-variable V3-V4 region of 16S rRNA gene of Eubacteria and Archaea were synthesized and used. The sequences of the PCR primers are V3F: 5'-CCTACGGGNGGCWGCAG-3' and V4R: 5'-GACTACHVGGGTATCTAATCC-3'. The target-amplicons were generated using a fusion-primer that consists of Illumina adaptors and multiplex-index sequence as per the manufacturer's instructions (Illumina Inc. San Diego, CA, USA). The ampliconlibraries were purified by 1X AMpureXP beads and checked on Agilent High Sensitivity (HS) chip on Bioanalyzer 2100 and quantified on fluorometer using Qubit dsDNA HS Assay kit (Life Technologies, California, USA). Quality passed libraries were equimolar pooled and then sequenced using the Illumina MiSeq platform with $300 \times 2$ pair-end sequencing chemistry following the manufacturer's protocols (Illumina, San Diego, CA, USA).

\section{Metagenomic bioinformatic analysis}

Initially, the sequenced raw forward-reads (R1) and reverse-reads (R2) from all samples were visualized using the FastQC version [35] to screen the quality statistics of the 16S rRNA gene amplicon reads (https://www.bioinformatics.babraham.ac.uk/projects/fastqc/). The raw-reads were, then, curated to remove poor-quality reads to obtain high-quality reads using Trimmomatic v0.35 [36] with parameters to i) remove adapter sequences, and ii) curate ambiguous reads (reads with unknown nucleotides " $N$ " larger than $5 \%$ ), low-quality sequences (reads with more than $10 \%$ quality threshold (QV) < 20 Phred score) (http://www.usadellab.org/cms/?page=trimmomatic). The final quality passed read-pairs were joined using PEAR (Paired-End reAd mergeR) version 0.9.8 (https://cme.h-its.org/exelixis/web/software/pear/) with default parameters. The joined paired-reads were processed for the downstream taxonomic classification; the unpaired reads were discarded. The taxonomic classification of the final high-quality reads was performed using MG-RAST v4.0 (https://www.mg-rast.org/), wherein 1) 16S rRNA featured reads were sorted using SortmeRNA, 2) sorted reads were clustered at $\geq 97 \%$ similarity using CDHIT method, and then 3) clustered reads were taxonomically classified against SILVA SSU database (https://www.arb-silva.de/). The classified reads/ taxon abundance downloaded $>100$ bases and $90 \%$ similarity through best hit classification.

\section{Metagenome statistical analysis}

Statistical Analysis of Metagenomic Profile (STAMP; V 2.9) (https://beikolab.cs.dal.ca/software/STAMP) was referred to determine microbial diversity and abundance in the phyllosphere. Welch-T-test and Post-Hoc Test at a confidence interval of $\geq 95 \%$ was followed. Further, Microbiome Analyst [37] was utilized for the determination of a-diversity, and $\boldsymbol{\beta}$ - diversity, as well as to identify core-phyllomicrobiome (https://www.microbiomeanalyst.ca/). For this, initially, reads were rarefied on minimum library size (18000 reads, minimum classified read in a sample), and then total sum scaling (TSS) was applied for data normalization. a- diversity significance was calculated using ANOVA test; Principal Coordinate Analysis (PCoA) was performed using Analysis of similarities (ANoSIM) based on Bray-Curtis method. The biomarker features were determined through the Linear discriminant analysis (LDA) combined with effect size measurements (LDA-LEfSe) approach at significance P<0.05 and LDA score $>2.0$ (http://huttenhower.sph.harvard.edu/lefse/). Bacterial genera co-occurrence network was analysed using SparCC method with the significance of $\mathrm{P}<0.05$ and strong correlation coefficient R2 $>0.60$ or $<-0.6$ (http://github.com/scwatts/FastSpar).

\section{Microscopic visualization of rice phyllomicrobiome}

Scanning Electron Microscopy: Scanning electron microscopy (SEM) was adopted for visualization of rice phyllomicrobiome following the method of Bozzola [38]. For SEM, rice leaves were cut into small pieces $\left(3 \mathrm{~mm}^{2}\right)$ and fixed in $2.5 \%$ glutaraldehyde for $12 \mathrm{~h}$ at $4.0^{\circ} \mathrm{C}$, rinsed in phosphate buffer saline (PBS-0.1 M, pH 7.2) for 10 min. Leaves were then dehydrated through graded series of $70,80,90,95$, and $100 \%$ acetone and then dried with a chemical dryer. The leaf preparations were, then, mounted on aluminum stubs using silver adhesive tape and sputter-coated with gold: palladium alloy (18 $\mathrm{nm}$ ) for $30 \mathrm{~min}$ consisting of 10 cycles of three min each for uniform coating (SC 7620 Emitech sputter-coater with a pressure of $10^{-1}$ mbar). Thus prepared leaf samples were examined and visualized under Scanning Electron Microscope (Zeiss EVO MA 10; Oxford Technologies) at $20.00 \mathrm{kV}$ and magnifications ranging from 4 $\mathrm{KX}$ to16 KX. The entire leaf surface was screened and searched for the possible presence of bacterial cells and images were captured.

\section{Culturing of phyllomicrobiome by microbiological methods}

Isolation and characterization of the cultivable phyllomicrobiome of rice: Another set of the leaf samples (500 mg) collected from the two rice genotypes were subjected to phyllomicrobiome isolation on nutrient agar [NA, gL ${ }^{-1}$ Peptone 5.0; Beef extract 3.0; NaCl 5.0; Agar 15.0; pH 7.0 \pm 0.2 ] and M9 minimal media [2 
$\mathrm{mM} \mathrm{MgSO}_{4} ; 0.1 \mathrm{mM} \mathrm{CaCl}_{2} ; 0.3 \%$ Glucose; $1.5 \%$ Agar; $1 \times \mathrm{M} 9$ salts $\left(5 \times \mathrm{M} 9\right.$ salts gL-1 $\mathrm{Na}_{2} \mathrm{HPO}_{4} .7 \mathrm{H}_{2} \mathrm{O} 64.0 ; \mathrm{KH}_{2} \mathrm{PO}_{4} 15.0, \mathrm{NaCl}_{2.5}$; $\left.\mathrm{NH}_{4} \mathrm{Cl} 5.0\right)$ ]. Briefly, the leaf was shaken with $50 \mathrm{ml}$ of sterile phosphate buffer saline amended with $0.1 \%$ tween-20 (PBS-T) for 30 minutes at 250 revolutions per minute followed by vortexing for 10 seconds. The aliquot, thus, obtained was decimally diluted up to $10^{-5}$. Aliquots of $1.0 \mathrm{ml}$ at $10^{-3}, 10^{-4}$, and $10^{-5}$ from each sample were pour plated into nutrient agar and M9 minimal media supplemented with 2, 3, 5 triphenyl tetrazolium chloride $\left(50 \mathrm{mg} \mathrm{L}^{-1}\right)$ to assist the morphotyping of the bacterial communities. The plates were incubated at $28^{\circ} \mathrm{C} \pm 2{ }^{\circ} \mathrm{C}$ for 72 hours. The experiment was conducted with three biological and three technical replications. The bacterial colonies were counted and isolated based on their morphology (size, shape, colour, texture, and margin). Later on, a single representative colony of each-morphotype was sub-cultured, purified and frozen-way in $-80{ }^{\circ} \mathrm{C}$ and $-20^{\circ} \mathrm{C}$ as glycerol stock ( $30 \% \mathrm{~V} / \mathrm{V}$ ). Species richness and the Shannon-Wiener diversity index $(\mathrm{H})$ were determined for the cultured bacterial communities.

\section{Molecular diversity analysis and identification of phyllomicrobiome associated bacterial species}

BOX-PCR DNA fingerprinting: Genomic DNA of each of the bacterial isolates was isolated by the CTAB method prescribed by Moore et al [34]. Isolated and purified genomic DNA was quantitated and quality checked electrophoretically and spectrophotometrically (NanoDrop 2000, ThermoScientific, USA). Finally, the genomic DNA was reconstituted at $100 \mathrm{ng} \mathrm{\mu l}^{-1}$ and used as a template in PCR amplification. Box-PCR based DNA-fingerprinting was performed for diversity analysis as well to eliminate the duplicate isolates from the collection [39]. The BOX-PCR amplicon profiling technique specifically amplifies the noncoding conserved sequences in the bacterial genome and is considered a highly discriminatory DNA fingerprinting technique for bacteria [40, 41]. Amplicons were resolved in $1.0 \%$ agarose gel at 30 volts for 10-12 hours and image-captured (QuantityOne, BioRad Laboratories, USA). Isolates showing identical amplicon profiles were presumed to be duplicates and represented one BOX-Amplicon Group. One representative isolate from each BOX-Amplicon Group was eventually used in the downstream work.

16S rRNA gene sequencing: Amplification of 16S rRNA gene was performed using universal primers 27F (27F: 5'-AGAGTTTGATCCTGGCTCAG-3') and 1492R (1492R: 5'-GGTTACCTTGTTACGACTT-3') to amplify the 1465 bp region to establish bacterial identity [42, 43]. Then, the PCR products resolved in $1.0 \%$ agarose gel were excised from the agarose gel and eluted using a gel elution kit (Wizard® SV Gel and PCR Clean-Up System) according to the manufacturer's instructions (Promega Corporation, USA). The cycle-sequencing reaction was performed using 20-30 ng of the purified amplicon using the ABI PRISM BigDye Terminators v3.1 cycle sequencing kit (Applied Biosystems Foster City, CA, USA) according to the manufacturer's instruction. The purified product was sequenced bi-directionally to obtain maximum coverage of the spacer region. The sequences were end trimmed, edited, and contig assembled using DNAbaser (http://www.dnabaser.com/download/DNA-Baser-sequence-assembler/). The curated sequences were, further, subjected to Basic Local Alignment Search Tool analysis (NCBI nucleotide BLAST) to establish their identity by closest match (https://www.ncbi.nlm.nih.gov/nucleotide/). All curated 16S rRNA gene sequences of phyllosphere bacterial species were submitted to GenBank database and assigned accession numbers.

\section{Functional screening of phyllosphere bacterial communities}

In vitro antifungal activity on Magnaporthe oryzae. Volatile and secretory metabolite mediated antagonistic assay of bacterial isolates were conducted on $M$. oryzae (isolate 1637) by dual-culture confrontation method. The percent inhibition of mycelial growth over mock was estimated by adopting the methods described by Sheoran et al [42] and Munjal et al [43]. Additionally, the fungicidal or fungistatic nature of the bacterial volatiles on $M$. oryzae was also determined. Briefly, bacterial isolates found completely inhibiting the growth of $M$. oryzae were further allowed to reestablish mycelial-growth. Based on the regrowth of the mycelium, the bacterial volatile were either categorized as fungicidal or fungistatic.

The radial growth of the fungus was measured and percent inhibition of growth over control was calculated with the help of the following formula

$$
\mathrm{I}=\frac{\mathrm{C}-\mathrm{T}}{\mathrm{C}} \times 100
$$

Where $\mathrm{I}=$ percent inhibition

$\mathrm{C}=$ Colony diameter in control

$\mathrm{T}=$ Colony diameter in treatment

In planta blast suppressive activity: The bacterial isolates significantly antagonistic to blast fungus in vitro were selected for this assay. Blast susceptible rice genotype, Pusa Basmati-1, was allowed to germinate in bacterial cell suspension $\left(2 \times 10^{7} \mathrm{CFU} \mathrm{mL}^{-1}\right)$ for five days. Upon germination, the transplants were, further, grown in a climate-controlled greenhouse set at temperature $28^{\circ} \mathrm{C} \pm 2{ }^{\circ} \mathrm{C} / \mathrm{RH} 90 \pm 10 \%$ /Light/dark cycles $14 / 10 \mathrm{~h}$. Seedlings were foliar sprayed with

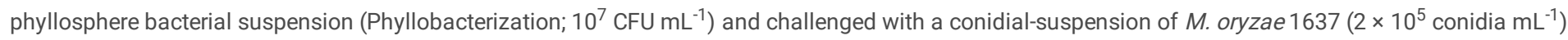
three weeks post sowing according to the protocols of Rajashekara et al [44]. Blast disease index was determined seven days post-inoculation using a $0-5$ disease rating-scale where $0=$ no evidence of infection; $1.0=$ brown specks smaller than $0.5 \mathrm{~mm}$ in diameter; $2.0=$ brown-specks of $0.5-1.0 \mathrm{~mm}$ in diameter; $3.0=$ roundish to elliptical lesions of about $1.0-3.0 \mathrm{~mm}$ in diameter; $4.0=$ typical spindle-shaped blast lesion, $3 \mathrm{~mm}$ or longer with little or no coalescence of the lesion; $5.0=$ same as 4.0 but half or more leaves killed by coalescence of lesions. Plants rated 0.0-2.0 were considered resistant, 3.0 as moderately susceptible, and 4.0-5.0 were considered susceptible [45]. The disease severity was calculated using the following formula.

\section{Disease severity}

$\sum($ scale $\times$ number of plants infected $) \times 100$

$=\frac{\sum(\text { total number of plants } \times \text { maximum disease scale }}{\text { time }}$ 
Further, the percent reduction in disease severity as compared to control was estimated using the following formula.

RDS $=\frac{\mathrm{C}-\mathrm{T}}{\mathrm{C}} \times 100$

Where RDS = Reduction in Disease Severity $(\%)$

$\mathrm{C}=$ Disease Severity in control

$\mathrm{T}=$ Disease Severity in treatment.

In planta rice defense gene(s) activation: Having observed the antifungal blast suppressive potential of phyllosphere core-bacterial communities on rice, qPCR experiments were conducted to decipher the leaf phyllobacterization effects on transcriptional changes in defense pathways in rice. Six phyllosphere bacterial isolates namely, Pantoea ananatis OsEp-PIm-30P3;Pantoea ananatisOsEp-PIm-30P21;Pantoea ananatisOsEp-AN-30A8;Aureimonas sp. OsEp-PIm30P7; Pantoea eucrina0sEp-PIm-30P10 andPseudomonas putidaOsEp-PIm-15P11 showing significant blast disease suppression were selected for the study. Briefly, whole seedlings of Pusa Basmati- 1 bacterized with $2 \times 10^{7} \mathrm{CFU} \mathrm{mL}^{-1}$ sampled at 24,48 , and 72 hours were immediately snap-frozen using liquidnitrogen (to arrest all the cellular activity) and then stored instantly at $-80^{\circ} \mathrm{C}$ till further use. Total RNA was isolated using the SV Tool RNA Isolation System according to the manufacturer's instruction (Promega, Madison, USA). The quality and quantity of RNA were assessed spectrophotometrically (NanoDrop 2000, ThermoScientific, USA) as well as by agarose gel electrophoresis. The experiment was repeated two times with three technical replications.

Candidate defense genes: Putative defense genes, OsCEBiP [46], OsCERK1 [47], OsPAD4 [48], OsEDS1 [49], OsNPR1 [50], OsPDF2.2 [51], OsFMO1 [52, 53] and OSPR1.1 [54] were chosen; PCR primers targeting the above defense genes are presented (Supplementary Table 1-2). The qPCR experiment was conducted in a Real-Time PCR instrument (Light Cycler 96, Roche Life Science, Switzerland) using GoTaq ${ }^{\circledR}$ 1-Step RT-qPCR System; qPCR reaction conditions were as follows; one cycle of reverse transcription at $37^{\circ} \mathrm{C}$ for 15 minutes followed by reverse-transcriptase inactivation step of $95^{\circ} \mathrm{C}$ for 10 minutes followed by 30 cycles of $95^{\circ} \mathrm{C}$ for 10 seconds, annealing at $58^{\circ} \mathrm{C}$ for 30 seconds and extension at $72{ }^{\circ} \mathrm{C}$ for 30 sec followed by three-step melting of $95^{\circ} \mathrm{C}$ for 10 seconds, 63 ${ }^{\circ} \mathrm{C}$ for 60 seconds and $97^{\circ} \mathrm{C}$ for 1 second and then final cooling at $37^{\circ} \mathrm{C}$ for 30 seconds. The expression levels of all eight defense-genes were calculated with reference to the expression of a housekeeping gene, OsActin, for normalization in different samples. Then, the qPCR data were analysed using LightCycler ${ }^{\circledR} 96$ Roche SW 1.1 software, and the mean Ct values were considered for calculation of $2^{-\triangle \Delta C T}$ to estimate the fold changes in gene -expression. The fold-change data were interpreted as value $\mathbf{1 . 0}$ for no change, $\geq \mathbf{2 . 0}$ represents significant upregulation, $\leq \mathbf{1 . 0}$ is down-regulation, and $\leq \mathbf{0 . 5}$ for significant down-regulation.

\section{Statistical analyses}

All the experimental data were analyzed using the data analysis tool available in MS office excel 2007. The data obtained were subjected to significance analysis by analysis of variance (ANOVA) at $p \leq 0.05$ level of significance. Further, various parameters like the standard error of the mean (SEm), standard error of the difference between two means (SEd), the critical difference (CD), coefficient of variation (CV) were calculated. For figures and tables, the values are represented as the mean of all biological and technical replicates.

\section{Results}

\section{Rice phyllomicrobiome samples, metagenome read statistics and diversity-indices}

Phyllomicrobiome profiles of PRR 78 (Blast susceptible) and Pusa 1602 (Blast resistant) grown in two contrasting agro-climatic zones were analysed and decoded by integrated mNGS and microbiological methods (Fig. 1). A total of eight-samples, namely, (i). Palampur-PRR 78-2016 (PRR 78-PIm1 \& PRR 78Plm2); (ii). Palampur-Pusa 1602-2016 (Pusa 1602- PIm1 \& Pusa 1602- PIm2); (iii). ANI-PRR 78- 2017 (PRR $78-$ ANI1 \& PRR $78-$ ANI2); (iv). ANI-Pusa 1602-2017 (Pusa 1602-ANI1 \& Pusa 1602-ANI2) were generated and subjected to microbiome analysis (Supplementary Table 3). The alpha-diversity indices of phyllosphere-microbial diversity determined using the mNGS data are furnished in Table 1. While the Shannon diversity index ranged from 2.12 to 3.15 , the Simpson and Chao1 are in the range of 0.729 to 0.896 and 128.11 to 300.61 , respectively. The observed species was in the range of $111-267$. The maximum diversity and maximum number of OTUs were found in most of the samples generated from the Island zone (Fig. 2; Table 1).

PCoA based Bray Curtis and ANoSIM

PCoA of metagenome reads of contrasting rice genotypes, PRR 78, and Pusa 1602 by Bray-Curtis and ANoSIM revealed converging and shared microbiome assemblage on rice genotypes when grown in the same agroclimatic-zone. The same genotype, either PRR 78 or Pusa 1602 , showed diverging-microbiome composition when grown in another agroclimatic zone, either Mountain or Island-zone (Fig. 3).

\section{Linear discriminant analysis (LDA) effect size (LEfSe) analysis}

The LDA-LEfSe score calculated at 2.0 significance level revealed microbial-biomarker profiles for rice genotypes and agroclimatic zones. The result showed a total of 10 biomarkers for Pusa 1602 and two for PRR 78. Klebsiella and Exiguobacterium were found to be a unique microbial biomarker for PRR 78 while Methylobacterium, Janibacter, Frankia, Macrococcus, Leptolyngbya, Shigella, Pseudacidovorax, Anoxybacillus, and Cellulosimicrobium were predicted to be a biomarker of Pusa 1602. For the geographical location, a total of 15 biomarkers for the mountain zone at Palampur and 16 for the Island zone for Port Blair samples were deciphered. Pantoea, Arthrobacter, Acidovorax, Erwinia, Microbacterium, Shewanella, Acinetobacter, Sphingobacterium, Pseudoalteromonas, Herbaspirillum, Psychrobacter, Candidatus-Koribacter, Mesorhizobium, Variovarax, and Roseateles were found to be a biomarker for mountain zone while, 
Lysinibacillus, Alkaliphilus, Cylindrospermum, Enterococcus, Bifidobacterium, Arthrospira, Leptolyngbya, Candidatus-Aquiluna, Agromyces, Lactobacillus, Leifsonia, Clostridium, Streptomyces, Bacillus, and Curtobacterium were identified as a biomarker for island zone (Supplementary Fig. 1).

SparCC network of variety and location

Network analysis showed the positive (cooperative) and negative (competitive) interactions within the phyllomicrobiome members on the phyllosphere. In agroclimatic zones and rice genotypes, as many as 68 bacterial genera were predicted to interacting among themselves showing positive and negative interactions on the phyllosphere (Supplementary Table 4; Supplementary Fig. 2). SparCc based network analysis of phyllomicrobiome showed 128 and 127 cooperative interactions on the rice genotypes and agro-climatic zones, respectively; as many as 104 and 108 competitive interactions were also predicted on the genotypes and climatic zones.

Comparative mNGS analysis of contrasting rice genotypes

The bacterial taxa can be considered as a member of "core microbiota" if it is "consistently" associated with all genotypes of a particular species. All other bacterial species may belong to "satellite microbiota" members. Comparative mNGS analysis of rice genotypes revealed the dominance of Proteobacteria, Firmicutes, and Actinobacteria on both the rice genotypes. A total of 11 phyla were found predominated in Pusa 1602 compared to PRR 78; they were Deinococcus-Thermus, Aquificae, Gemmantimonadetes, Chloroflexi, Acidobacteria, Planctomycetes, Verucomicrobia, Actinobacteria, Proteobacteria, Bacteroidetes, and Nitrospirae. On the other hand, only three phyla Firmicutes, Fusobacteria, and Cyanobacteria were found predominated in PRR 78 (Supplementary Fig. 3). Phyllomicrobiome profiles of all taxonomic hierarchies are furnished in Supplementary Fig. 3. Phyllomicrobiome at genus level showed primarily Pantoea followed by Curtobacterium, Methylobacterium, Exiguobacterium, and Bacillus on Pusa 1602; PRR 78 showed the dominance of Exiguobacterium followed by Pantoea, Sphingomonas, Curtobacterium, and Arthrobacter(Table 2; Fig. 4).

Comparative mNGS analysis of contrasting agroclimatic zones

Comparative mNGS analysis of rice genotypes of two climatic-zones at mountain and island zones revealed the dominance of Proteobacteria, Firmicutes, and Actinobacteria over other phyla on the rice phyllosphere (Supplementary Fig. 4; Supplementary Fig. 5). The comparative mNGS analysis further revealed the dominance of seven phyla each in Port Blair and Palampur samples. Whereas Actinobacteria, Aquificae, Chloroflexi, Cyanobacteria, Nitrospirae, Planctomycetes, and Verucomicrobia were found on the Island zone, the mountain zone showed the presence of Acidobacteria, Bacteroidetes DeinococcusThermus, Gemmantimonadetes, Firmicutes, Fusobacteria, and Proteobacteria (Supplementary Fig. 4; Supplementary Fig. 5). Unique phyllomicrobiome profiles for mountain and island agroclimatic zones showing taxonomic hierarchies such as class, order, and family are presented in Supplementary Fig. 4 and Supplementary Fig. 5. The genera-level comparative microbial profile revealed the predominance of Bacillus, Curtobacterium, Exiguobacterium, Pantoea, and Sphingomonas at the Island zone while the rice phyllosphere in the mountain zone was dominated by Arthrobacter, Exiguobacterium, Methylobacterium, and Pantoea over other bacterial genera (Table 2; Fig. 4; Fig. 5; Supplementary Fig. 6).

Core microbiome analysis

Core-microbiome at the genus level was analyzed for rice genotypes as well as for the agroclimatic zones. Core microbiome of blast susceptible genotype, PRR 78 was found consisting of 17 bacterial genera with a maximum prevalence of Pantoea, Klebsiella, and Exiguobacterium. Blast resistant genotype Pusa 1602 showed core microbiota composed of 19 genera with the maximum prevalence of Pantoea, Methylobacterium, and Exiguobacterium. For agroclimatic zones, the core phyllomicrobiome at the mountain zone was found comprising of 20 genera with the high representation of Pantoea, Microbacterium Exiguobacterium, and Arthrobacter. Similarly, the core phyllomicrobiome at the Island zone displayed 16 genera with the maximum prevalence of $P$ antoea, Methylobacterium, Exiguobacterium, Curtobacterium, and Bacillus.

Overall, the core phyllomicrobiome of rice deduced from all sets of samples revealed $\mathbf{2 6}$ bacterial genera with the maximum prevalence of Pantoea and Exiguobacterium. The other member of rice core phyllomicrobiome were Methylobacterium, Curtobacterium, Sphingomonas, Microbacterium, Bacillus, Klebsiella, Arthrobacter, Hymenobacter, Deinococcus, Pseudomonas, Nocardioides, Kineococcus, Erwinia, Cronobacter, Clavibacter, Acidovorax, Streptomyces, Serratia, Salmonella, Pedobacter, Methylocella, and Clostridium (Table 3).

Scanning Electron Microscopic imaging of phyllomicrobiome

The SEM imaging of rice phyllomicrobiome revealed the physical presence of bacterial cells aggregates of 5-8 cells, and unevenly distributed solitary bacterial-cells on the phyllosphere of rice genotypes. The Eukaryotic cells and hyphal fragments were also found scattered among the prokaryotic cells (Fig. 6).

Culturable phyllomicrobiome analysis

Enumeration, characterization, and identification of rice phyllomicrobiome associated bacterial communities: Susceptible genotype (3.127 - 4.313 CFU $\mathrm{g}^{-1}$ ) recorded the higher epiphytic bacterial population as compared to resistant genotypes (2.945 - $3.317 \mathrm{CFU} \mathrm{g}^{-1}$ ) in both locations (Supplementary Table 5; Supplementary Table 6). A total of 78 distinct morphotypes of cultured bacterial communities were isolated from both locations. A relatively more bacterial population was found on 30 days old phyllosphere (45 morphotypes) as compared to 15 days (33 morphotypes). The results of diversity indices indicated that the blast susceptible genotype and 30 days old phyllosphere recorded significantly more bacterial diversity than the resistant genotype and 15 days old phyllosphere. The Shannon diversity index ranged from 1.12 to 1.8 for all the cultured phyllosphere microbiome. The diversity indices of epiphytic bacteria isolate colonized rice phyllosphere representing three locations are presented in Table 4. BOX-PCR DNA fingerprinting of all 78 morphotypes culminated in 59 distinct BOX Amplicon Groups. At least in one BOX-amplicon group, the amplicon profiles were found perfectly identical for isolates OsEp-PIm-15P4; OsEp-

Page $7 / 28$ 
PIm-15P8; OsEp-PIm-15P9; OsEp-PIm-15P10; OsEp-PIm-15P13; OsEp-PIm-15P15 from mountain zone, and for isolates, OsEp-AN-15A10; OsEp-AN-15A11; OsEp-AN-15A17; OsEp-AN-15A18 representing island zone. One of each isolates, OsEp-PIm-15P9 and OsEp-AN-15A10, representing the mountain zone and island zone, respectively were selected for further work (Supplementary Figure 7). Isolates with identical amplicon profiles were considered duplicates. 16S rRNA gene sequence-based database searches for isolated bacterial species revealed the high-frequency occurrence of Acidovorax (3), Acinetobacter(6), Aureimonas (2), Curtobacterium (5), Enterobacter (6), Exiguobacterium (4), Microbacterium (2), Pantoea (16), Pseudomonas (5) and Sphingomonas (7) on rice phyllosphere (Supplementary Figure 8;Supplementary Table 7). Six bacterial isolates from the mountain zone and four from the island zone (represented by OsEp-PIm-15P9 and OsEp-AN-15A10) which shared all BOX PCR amplicons (genetically identical isolates) were identified as Pantoea ananatis.

Microbiological validation of phyllomicrobiome profile and isolation of core microbiome

A total of 59 bacterial species belonging to 14 diverse bacterial genera such as Acidovorax, Acinetobacter, Agrobacterium, Aureimonas, Curtobacterium, Enterobacter, Enterococcus, Erwinia, Exiguobacterium, Microbacterium, Micrococcus, Pantoea, Pseudomonas, and Sphingomonas were cultured, isolated, and preserved from rice phyllomicrobiome (Supplementary Figure $9 \mathrm{a}-9 \mathrm{~m}$ ). All cultured bacterial flora were also found among the mapped reads in the mNGS data. Further, comparative analysis of phyllomicrobiome of rice samples confirmed the consistent association of Acinetobacter, Curtobacterium, Enterobacter, Exiguobacterium, Pantoea, Pseudomonas, and Sphingomonas in Mountain and Island agroclimatic zones in both the mNGS and microbiological approaches (Data not shown). Bacterial genera such as Acinetobacter, Curtobacterium, Enterobacter, Exiguobacterium, Pantoea, Pseudomonas, and Sphingomonas were consistently associated with both the genotypes in all samples (data not shown).

Activity screening for identification of functional core-phyllomicrobiome

Screening for antifungal activity: Dual plate confrontation assay showed inhibition of mycelial growth of $M$. oryzae by both volatiles and secreted metabolites produced by bacterial species. Among the 59 bacteria evaluated, 14 phyllosphere-associated bacterial isolates ( $23.7 \%$ ) displayed over $40.0 \%$ inhibition of mycelial growth by their secreted metabolites (Table 5; Supplementary Fig. 10). The antagonistic bacterial isolates represented species such as Acinetobacter baumannii; Acinetobacter soli; Erwinia tasmaniensis; Exiguobacterium indicum; Pantoea agglomerans; Pantoea ananatis; Pantoea dispersa; Pantoea eucrina; andPseudomonas oryzihabitans. Similarly, a total of 15 of them (25.4\%) inhibited the growth of $\boldsymbol{M}$. oryzae completely by airborne bacterial volatile organic compounds (BVCs) (Table 5; Supplementary Fig. 11). The antifungal volatile releasing bacterial isolates represented the species such as Acinetobacter baumannii; Acinetobacter soli; Aureimonas sp.; Pantoea agglomerans; Pantoea ananatis; Pantoea dispersa; Pantoea eucrina; Pseudomonas parafulva, Pseudomonas putida; and Pseudomonas oryzihabitans. Further, the BVCs of five bacterial isolates were found to show fungicidal activity while the remaining 10 were fungistatic on M. oryzae(SupplementaryTable 6; Supplementary Fig. 12).

Screening for blast disease suppression: Blast susceptible rice cultivar, Pusa Basmati 1, was used for evaluating the anti-blast activity of rice phyllomicrobiome associated bacterial communities on blast disease incited by $M$. oryzae. A total of 20 bacterial strains were selected based on in vitro inhibition of M. oryzae. The isolates represented bacterial genera such as Pantoea (12 strains), Pseudomonas (2), Acinetobacter(3), Aureimonas (1), Erwinia (1), andExiguobacterium (1). Rice seeds germinated in the presence of bacterial cells $\left(2 \times 10^{7} \mathrm{CFU} \mathrm{mL}^{-1}\right)$ were allowed to grow in a climate-controlled greenhouse and challenged with $M$. oryzae. Before pathogen challenge inoculation, a booster dose of bacterial cell suspension was sprayed onto the leaf lamina. Blast incidence and severity were scored as per the blast score chart recommended by Mackill and Bonman [43]. Most of the bacterial isolates were found to reduce the blast disease development in the plants of the susceptible rice cultivar. Maximum reduction in disease severity was shown by Pantoea ananatis OsEp-PIm-30P3 (74.3\%), Pantoea ananatis OsEp-PIm-30P21 (74.2\%), Pantoea ananatis OsEp-AN-30A8 (73.0\%.), Aureimonas sp.0sEp-PIm-30P7 (73.0\%),Pantoea eucrina OsEp-PIm-30P10 (71.5\%),Pseudomonas putida OsEp-PIm-15P11 (51.8 \%), Pantoea ananatis OsEp-PIm-15P9 (49.7\%), and Acinetobacter baumannii OsEp-PIm-30P11 (47.3\%) (Table 6; Fig. 7;Supplementary Fig. 13).

Phyllosphere bacteria-induced expression of defense genes in rice

Seven candidate plant defense genes i.e. OsCEBiP, OsCERK1, OsPAD4, OsNPR1, OsPDF2.2, OsFM01, and OsPR1.1 showed marginal to a high level of expression in phyllobacterised rice seedlings as compared to the reference gene, OsActin. Interestingly, all six phyllosphere bacterial species such as Pantoea ananatis OsEp-PIm-30P3; Aureimonas sp. OsEp-PIm-30P7; Pantoea eucrina OsEp-PIm-30P10; Pantoea ananatis OsEp-PIm-30P21; Pseudomonas putida OsEp-PIm-15P11 and Pantoea ananatis OsEp-AN-30A8 triggered consistent over-expression of OsCEBiP in rice seedlings. Significant induction of OsCEBiP, OsCERK1, and OsPAD4 was observed in rice seedlings sprayed with Pantoea or Aureimonas. Strikingly, Aureimonas sp. OsEp-PIm-30P7 showed significant and sustained over-expression of OSCEBiPn 24, 48, and $72 \mathrm{hpi}$. The epiphytic bacteria-inoculation mediated activation of defense genes was more pronounced during early time points peaking at $48 \mathrm{hpi}$ with a sharp drop at $72 \mathrm{~h}$ of bacterial interaction (Fig. 8; Supplementary Fig. 14; Supplementary Table 9).

\section{Discussion}

Plant microbiological explorations in the past have revealed highly complex microbial 'assemblages and networks' associated with different plants and specific plant niches termed as plant holobiont. The plant physiological and ecological functions are, therefore, modulated holistically by plant holobiont (and the plant microbiomes). The microbiome in the rhizosphere, phyllosphere, spermosphere, and endosphere has vital ecological functions supporting plant life. It is also believed that the plants continuously recruit and renew their microbial partners on epiphytic and endophytic niches. Herein, microbial succession is predicted to play a contributory role in plant ecology. Metagenome, the total genomic contents of microbiota, and that of plant-genome are presumed to possess diverse metabolic capabilities usually not found in plants per se.

Plant microbiome plays a versatile ecosystem function by their competitive and cooperative activities leading to nutrient-cycling, plant growth, and health [3, 55-59]. Mills et al [59] proposed a concept of keystone microbial species which is central to the microbial community assemblage and the sustainability of

Page $8 / 28$ 
the ecological niche. Adapted microbial communities developing an intimate association with that of plant species during their co-evolution are termed as core-microbiome (or core-microbiota) which is speculated to be vertically transmitted in successive generations of plants [60]. Nevertheless, microbiome composition on a plant niche is influenced by plant genotype, habitat, ecosystem, as well as macro and micro-climatic conditions [61]. It is further reported that long-term seasonal patterns related to climatic variations serve a vital role in shaping the phyllosphere microbiome as compared to short-term weather fluctuations during crop season [62].

The plant phyllosphere is one of the habitats for diverse microorganisms that are adapted to survive intra-day vagaries of weather as well as the nutrientdepleted niches. However, the major drivers of phyllosphere microbiome structure and composition are not adequately understood. Although speculated from the microbiome profile of multiple genotypes, the core-phyllomicrobiome of rice is not elucidated thoroughly. We attempted to integrate both mNGS and microbiological strategies to characterize the core phyllomicrobiome of the rice genotype. For this, first, we sequenced phyllosphere metagenome of two rice genotypes contrasting for their reaction to blast disease grown in two contrasting agroclimatic zones of India namely, the Mountain zone in the Himalayan Hill and the Island zone in the Andaman Island situated in the Bay-of-Bengal. Uniquely, the phyllomicrobiome in our study represented blast susceptible genotype PRR 78, and Pusa 1602 -the near-isogenic line of PRR 78, introgressed with Pi2 gene conferring complete resistance to blast disease. Most of the phyllomicrobiome studies, till now, focused mostly on profiling of microbiome using mNGS methods alone. Furthermore, very few attempts have been made to exploit the phyllomicrobiome for crop production and protection. Therefore, the ultimate goal of our investigation was to decipher the functional corephyllomicrobiome of rice for exploiting phyllomicrobiome assisted rice cultivation with a focus on blast disease management. While the blast mitigation strategy by R-genes is threatened by new pathotypes, the fungicide is environmentally unsafe and is no longer accepted in trade [30, 63]. Hence, there is a need for alternative approaches for blast disease management preferably through eco-friendly strategies.

mNGS-survey coupled with culturing-based validation revealed diverse bacterial flora on the phyllosphere of rice. Members belong to phyla such as Proteobacteria, Firmicutes, Actinobacteria, and Bacteroidetes were found consistently on phyllosphere of both the resistant and susceptible genotypes grown Mountain and Island zones; dominance phylum - Proteobacteria on phyllosphere is reported by many workers [64-66]. Recently, Roman-Reyna et al [67] found region-specific microbial hubs belonging to diverse bacterial families in rice after studying 3024 accessions. Families such as Bacillaceae,

Comamonadaceae, Enterobacteriaceae, Enterococcaceae, Kineosporiaceae, Methylobacteriaceae, Microbacteriaceae, Micrococcaceae, Moraxellaceae, Nocardiaceae, Paenibacillaceae, Pseudoalteromonadaceae, Pseudomonadaceae, Rhizobiaceae, Sphingomona -daceae, and Xanthomonadaceae contributed genera such as Acinetobacter, Arthrobacter, Bacillus, Curtobacterium, Enterobacter, Exiguobacterium, Kineococcus, Methylobacterium, Microbacterium, Paenibacillus, Pantoea, Pseudoalteromonas, Pseudomonas, Rhodococcus and Sphingomonas on the phyllosphere of both the genotypes in both the contrasting agro-climatic zones indicating their specific association with rice plant; they may represent core phyllomicrobiome of rice. Bacterial genera such

as Curtobacterium, Enterobacter, Methylobacterium, Microbacterium, and Sphingomonas are frequently reported as the core-spermosphere microbiome of rice [68, 69]. Kim et al [70] also reported dominance of Pantoea (42.5\%), Methlyobacterium (11.8\%), Curtobacterium (9.3\%), Pseudomonas (8.7 \%),

and Sphingomonas (8.6\%) on rice spermosphere. They also observed that the seed microbiome appeared to be highly stable and protected owing to their natural encapsulation in the seed coat that enables them to be inherited, known as vertical transmission.

The core-phyllomicrobiome assemblage observed in our study seems to be less or unaffected by local climatic conditions of either hill ecosystem or coastal ecosystem and genotype differences. Therefore, it is concluded that the spermosphere of PRR 78 and Pusa 1602 harboured a core-phyllomicrobiome consisting of Acinetobacter, Arthrobacter, Bacillus, Curtobacterium, Enterobacter, Exiguobacterium, Kineococcus, Methylobacterium, Microbacterium, Paenibacillus, Pantoea, Pseudoalteromonas, Pseudomonas, Rhodococcus, and Sphingomonas. According to Eyre et al [69] an ideal core microbiome is defined as the microbiota shared between genotypes grown in geographical areas that do not share common environmental conditions. The genotypes, PRR 78, and Pusa 1602 grown in contrasting agroclimatic zones representing the lower-Himalayan region and coastal Island region showed the consistent presence of bacterial genera that are reported as core seed microbiome. Along with the recent shreds of evidence from rice seed microbiomes, it is further speculated that the rice seeds played a carrier of microbiome which enabled its spatio-temporal transmission across diverse geographical locations and seasons.

Bacterial families Actinomycetaceae, Aerococcaceae, Burkholderiaceae, Caulobacteraceae, Corynebacteriaceae, Dietziaceae, Sphingobacteriaceae, and Staphylococcaceae were observed only in resistant rice genotype -Pusa 1602 in both the locations but not in blast susceptible genotype, PRR 78. Further, PRR 78 showed bacterial families Clostridiaceae, Intrasporangiaceae, and Oxalobacteraceae that were not observed in blast-resistant type, Pusa 1602. Therefore, they may be considered as genotype-specific phyllomicrobiome.

The impact of disease resistance conferring-gene (R-gene) introgression in cultivated crops on phyllomicrobiome composition and assemblage is recently reported [67]. The rice line IR24 introgressed with Xa4 gene conferring resistance to bacterial blight caused by Xanthomonas oryzae pv. oryzae showed a reduction in the abundance of Actinobacteria, but an increase in Proteobacteria and Firmicutes compared to IR24. Similarly, the rice line R711+SAox had a decrease in the abundance of Firmicutes and an increase in Proteobacteria. A significant influence of plant genotype on rhizosphere and endosphere microbiome is also reported by several workers [71-73].

Bacterial communities identified on rice phyllomicrobiome by mNGS were further validated by culture-based microbiological methods which yielded 78 bacterial morphotypes. More number of morphotypes was isolated from 30 days old rice seedlings as compared to 15 days old seedlings suggestive of the expansion of microbial biomass on plant niches upon aging. These isolates were further characterized using BOX-AIR-PCR fingerprinting that resulted in 59 discrete isolates based on the amplicon profile of the isolates. BOX-PCR is one of the frequently used molecular tools in bacterial typing and biogeography studies of microbial isolates [39, 74]. The BOX-PCR fingerprinted 59 phyllosphere bacterial isolates represented 13 genera and 29 species based closest match of 16S rRNA gene sequence in multiple databases. Interestingly, as many as six bacterial morphotypes from mountain-zone and four from tropical island-zone were found sharing all BOX-PCR amplicons; they can be considered as genetically identical isolates. The most frequented bacterial species in the cultivated phyllomicrobiome belonged to Acinetobacter, Acidovorax, Curtobacterium, Enterobacter, Pantoea, Pseudomonas, and Sphingomonas. We observed 
genetically identical Pantoea ananatis in the phyllomicrobiome obtained from the two agroclimatic zones. Interception of genetically identical OsEp-PIm15P9 and OsEp-AN-15A10 identified as Pantoea ananatisrepresenting contrasting and well-separated agroclimatic zones is indicative of vertical transmission of phyllomicrobiome. The evidence generated for vertical transmission of phyllomicrobiome may be attributed to rice seeds. Recently Charishma [75] reported high-frequency occurrence of Pantoea ananatis on rice spermosphere and phyllosphere of Pusa Basmati-1 and VLD85 by adopting dual mNGS and microbiological methods. Spermosphere microbiome seems to have spread to rice phyllomicrobiome pool during seedling emergence and further plant growth. Our data on seed transmission of phyllomicrobiome supported the observations of Kim et al [70]. Altogether, it may be concluded that rice spermosphere is among the primary sources of the core phyllomicrobiome, and the rice grown in contrasting geographical locations may have acquired the phyllomicrobiome from the spermosphere as well.

The core bacterial genera such as Acinetobacter(pale brown), Aeromonas (dark brown), Aureimonas(yellow), Curtobacterium (yellow; red), Exiguobacterium (yellow; orange), Methylobacterium (pink), Microbacterium (yellow), Micrococcus (yellow; red), Pantoea (yellow), and Sphingomonas (yellow) found consistently on phyllosphere are frequently reported pigment-producing species. Dark pigmentation is one of the adaptive traits of bacteria and other microbes in the phyllosphere $[61,76]$. The pigmentation of many Aeromonas species is attributed to the production of L-3, 4-dihydroxyphenylalanine (LDOPA) based melanin [77]. Rice foliar niche is frequently cited habitat for pink-pigmented-facultative -methylotrophic (PPFM) bacteria and yellow-pigmented Pantoea that is tolerant of harmful $\otimes$-ray radiation as well as nutritional and moisture stress [76]. Recently, Carvalho and Castillo [78] reported the significant role of sunlight in shaping the microbiome of the phyllosphere. The intimate association of Pantoea ananatis with the phyllosphere of many plants including rice plants is reported $[79,80]$. Microbacterium testaceum is reported to degrade $\mathrm{N}$-acyl-homoserine lactone on a potato leaf and is considered as an aggressive plant colonizer involved in natural biocontrol against plant pathogen [81]. Microbacterium has been reported in the rice phyllosphere and spermosphere [68, 82, 83]. The phyllomicrobiome data further revealed horizontal microbiome transmission from insects like Anopheles stephensi to rice as evident from the interception of Asaiara mosquito-associated bacteria on phyllosphere samples from Andaman Island that is endemic for malaria [84].

Techniques such as fluorescent in situ hybridization (FISH) and SEM are among the frequently used methods to visualize native microbial cells as well as to analyse the spatial distribution of microbial cells on phyllosphere [85, 86]. Our SEM imaging indicated the physical presence of bacterial cells aggregates of $5-8$ cells, and unevenly distributed solitary bacterial cells on the rice phyllosphere. The formation of aggregates or biofilms by bacterial communities is touted as one of the adaptive mechanisms on the nutrient-depleted harsh plant habitat like phyllosphere [10, 87].

The cultured core-phyllomicrobiome (59 isolates) displayed secretary compounds (SCs) or bacterial volatile compounds (BVCs) mediated antifungal activity on M. oryzae. Whereas Acinetobacter, Pantoea, and Pseudomonas inhibited M. oryzae by SCs and BVCs, the Aureimonas, Erwinia, and Exiguobacterium showed SC mediated antagonism. The antagonistic potential of these bacterial genera is frequently cited against diverse phytopathogens (Acinetobacter baumannii [88], Pantoea ananatis [89], Pantoea agglomerans [90], Pseudomonas oryzihabitans [91-93], Pseudomonas putida [42, 94]). While the majority is yet to be field-tested against plant diseases, the apple strain of Pantoea vagans C9-1 is registered as BlightBan C9-1 by Nufarms America Inc., Burr Ridge, IL, USA for biocontrol of fire blight caused by Erwinia amylovora. Significant reduction of blast disease in rice was observed with phyllobiome associated Pantoea, Aureimonas, Pseudomonas, and Acinetobacterapplied as a prophylactic phyllobacterization which can be attributed to antifungal antibiosis. Rice blast suppression by rhizospheric Bacillus, Streptomyces, Pseudomonas, Pantoea, Paenibacillus, Burkholderia Enterobacter, and Paraburkholderia is reported [95, 96]. Reduction of leaf blast severity by phyllosphere actinomycetes is also recently reported by Harsonowati et al [97].

Phyllobacterized plants showed an elevated expression of defense genes such as OsCEBiP, OsCERK, OsPR1.1, OsNPR1,OsPDF2.2, OsFMO, and OsPAD4; significant induction of OSCEBiP, OSCERK1, and OSPAD4 was observed in rice seedlings sprayed with Pantoea or Aureimonas. OsCEBiP and OsCERK1 are known to interact with chitin to activate MAMP Triggered Immune (MTI) responses in plants [46]. OsCERK1 is a receptor-like kinase (RLK) believed to perceive fungal-chitin and bacterial-peptidoglycan [47]. OSPAD4 and OSEDS1 play an important role in jasmonic acid-mediated induced systemic resistance. The accumulation of rice phytoalexin mamilactone-A is reported to be modulated by the expression of the OsPAD4 gene and is known to govern blast resistance $[48,49,98]$. Marginal induction of OSNPR1, OsFMO, OsPDF2.2, and OSPR1.1 was observed in bacterized seedlings. OsNPR1 is the central regulator of salicylic acid (SA)-mediated defense signaling which is also responsible for the reallocation of energy and resources during the defense response [50]. Similarly, OsFMO1 is also an essential component for induced systemic acquired resistance [52, 53]. OsPDF2.2 is a plant defensin responsible for the inhibition of the growth of fungi [51]. OSPR1.1 is an acidic pathogenesis-related protein, and a marker for salicylic acid-mediated SAR [54].

Black pepper endophyte, Pseudomonas putida BP25 has been recently reported to induce defense in rice plants against blast disease [94]. Similarly, Arabidopsis thaliana genes governing SA-mediated defense and growth promotion were found up-regulated by P. putida BP25 [99] and Bacillus megaterium BP17 [100]\{Vibhuti, 2017 \#61; Akamatsu, 2013 \#44\}. Species belonging to Microbacterium and Stenotrophomonas have also been recently reported to elicit defense against rice blast disease [101]. Patel et al [102] recently reported the antifungal and defense elicitation activity by BVC belongs to pyrazine against the rice blast disease.

\section{Conclusion}

A converging phyllomicrobiome assemblage was observed on rice genotypes grown in a particular agroclimatic zone. Conversely, rice genotype grown in contrasting agroclimatic zones displayed divergent phyllomicrobiome assemblage. Agroclimatic zone and the associated climatic factors rather than hostgenotype per se appears to drive phyllomicrobiome structure and composition on the rice genotypes. Our integrated approach revealed $A$ cinetobacter, Aureimonas, Curtobacterium, Enterobacter, Exiguobacterium, Microbacterium, Pantoea, Pseudomonas, and Sphingomonas as core phyllomicrobiome of rice. Genetically identical bacterial communities intercepted on the phyllosphere of rice grown in the contrasting agroclimatic zone are suggestive of spatiotemporal transmission of phyllomicrobiome aided by seed. The core microbiome mediated phyllobacterization showed potential for blast disease suppression which could be attributed to direct-antibiosis as well as indirect- elicitation of innate immunity in rice. The identification of phyllosphere adapted 
functional core-bacterial communities in our study and their co-occurrence dynamics presents an opportunity to devise novel strategies for rice blast management through phyllomicrobiome reengineering in the future.

\section{Abbreviations}

ANl: Andaman and Nicobar Islands

ANoSIM: ANalysis of SIMilarities

ANOVA: Analysis of variance

BVC: Bacterial Volatile Compounds

CD: Critical Difference

CFU: Colony Forming Units

CTAB: Cetyl Trimethyl Ammonium Bromide

CV: Coefficient of variation

Km: Kilometer

LDA-LEfSe: Linear discriminant analysis (LDA) effect size (LEfSe) method

MG-RAST: Metagenomic Rapid Annotations using Subsystems Technology

mNGS: Metagenomic Next-Generation Sequencing

NA: Nutrient Agar

NextGen-Crop-care: Next-Generation technology for crop health management

OTU: Operational Taxonomic Units

PBS: Phosphate Buffered Saline

PBS-T: Tween 20 amended Phosphate Buffered Saline

PCoA: Principal Coordinate analysis

PEAR: Paired-End reAd mergeR

Phyllobacterization: A term coined for spraying of bacterial cell suspension on phyllosphere

Phyllomicrobiome: Microbiome adapted on above-ground plant foliar parts including leaf

Phytosphere: Plant associated niche including epi and endophytic niches

PIm: Palampur, India

qPCR: Quantitative Real-Time PCR

RDS: Reduction in Disease Severity

SC: Secreted Compounds

SEd: Standard Error of the difference between two means

SEM: Scanning Electron Microscopy

SEm: Standard Error of the mean

STAMP: Statistical Analysis of Metagenomic Profile

TSS: Total Sum Scaling

\section{Declarations}


Our manuscript entitled "Deciphering core-phyllomicrobiome of rice genotypes grown in contrasting mountain and island agroclimatic zones: Implications for microbiome engineering against blast disease" complies with the Ethical Rules applicable for the journal.

\section{Consent for publication}

All authors have read the manuscript and consented to the publication

\section{Availability of data and material}

Data sets were submitted to NCBI GenBank with BioProject ID PRJNA681302. The data sets were also uploaded in MG-RAST server under project ID mgp94842 with following sample name and deposition numbers; PRR 78_PIm1 (mgm4895994.3); PRR 78_PIm2 (mgm4895995.3); Pusa 1602_PIm1 (mgm4895999.3); Pusa 1602_PIm2 (mgm4896000.3); PRR 78_ANI1 (mgm4895998.3); PRR 78_ANI2 (mgm4896001.3); Pusa 1602_ANI1 (mgm4895997.3); Pusa 1602_ANI2 (mgm4895996.3). All bacterial cultures and fungal isolate are available in the Division of Plant Pathology, ICAR-IARI, New Delhi.

\section{Competing interests}

The authors declared no conflict of interest

Funding

Kuleshwar Prasad Sahu offers sincere thanks to the Council of Scientific and Industrial Research (CSIR) for financial support in the form of Junior and Senior Research Fellowships (File No: 09/083(0367)/2016-EMR-I) for the Ph. D program. Kuleshwar Prasad Sahu and A. Kumar are grateful to NAHEP-CAAST on "Genomics assisted crop improvement and management" for financial assistance.

\section{Authors' contributions}

KPS and AK -Conceptualization, Methodology, Resources, and Validation; KPS, KS, RR, RKG -Carried out the field planting in Palampur and Port Blair, SG, AK Assisted in procuring rice genotypes and plant analysis; NS, MK, AP, GP, AK-assisted KPS in various lab experiments; AK-Supervised the work on a regular interval; BR, KPS, AK - Metagenome data analysis; AK, KPS- Data analysis and Manuscript preparation; All authors read and approved the final manuscript.

\section{Acknowledgments}

We thank the Director, IARI, and Dean, PG School, Indian Council of Agricultural Research-Indian Agricultural Research Institute, New Delhi for logistic support and encouragement. We gratefully acknowledge the research facilities provided by NAHEP-CAAST, ICAR-IARI, New Delhi.

\section{References}

1. Sessitsch A, Hardoim P, Döring J, Weilharter A, Krause A, Woyke T, et al. Functional characteristics of an endophyte community colonizing rice roots as revealed by metagenomic analysis. Mol Plant-Microbe Interact. 2012; 25(1): 28-36. https://doi.org/10.1094/mpmi-08-11-0204.

2. Bulgarelli D, Schlaeppi K, Spaepen S, Van Themaat EVL, Schulze-Lefert P. Structure and functions of the bacterial microbiota of plants. Annu Rev Plant Biol. 2013; 64:807-838. https://doi.org/10.1146/annurev-arplant-050312-120106.

3. Vorholt JA. Microbial life in the phyllosphere. Nat Rev Microbiol. 2012; 10(12): 828-840. https://doi.org/10.1038/nrmicro2910.

4. Lindow SE, Leveau JH. Phyllosphere microbiology. Curr Opin Biotechnol. 2002; 13(3): 238-243. https://doi.org/10.1016/s0958-1669(02)00313-0.

5. Bringel F, Couée I. Pivotal roles of phyllosphere microorganisms at the interface between plant functioning and atmospheric trace gas dynamics. Front Microbiol. 2015; 6: 486. https://doi.org/10.3389/fmicb.2015.00486.

6. Chinnadurai C, Balachandar D, Sundaram SP. Characterization of 1-aminocyclopropane-1-carboxylate deaminase producing methylobacteria from phyllosphere of rice and their role in ethylene regulation. World J Microbiol Biotechnol. 2009; 25(8): 1403-1411. https://doi.org/10.1007/s11274-0090027-1.

7. Janarthine S, Eganathan P. Plant growth promoting of endophytic Sporosarcina aquimarina SjAM16103 isolated from the pneumatophores of Avicennia marina L. Int J Microbiol. 2012; 2012. https://doi.org/10.1155/2012/532060.

8. De Costa DM, Samarasinghe SST, Dias HRD, Dissanayake DMN. Control of rice sheath blight by phyllosphere epiphytic microbial antagonists. Phytoparasitica. 2008; 36(1): 52-65. https://doi.org/10.1007/bf02980748.

9. Balint-Kurti P, Simmons SJ, Blum JE, Ballaré CL, Stapleton AE. Maize leaf epiphytic bacteria diversity patterns are genetically correlated with resistance to fungal pathogen infection. Mol Plant-Microbe Interact. 2010; 23(4): 473-484. https://doi.org/10.1094/mpmi-23-4-0473.

10. Lindow SE, Brandl MT. Microbiology of the phyllosphere. Appl Environ Microbiol. 2003; 69(4): 1875-1883. https://doi.org/10.1128/aem.69.4.18751883.2003.

11. Redford AJ, Bowers RM, Knight R, Linhart Y, Fierer N. The ecology of the phyllosphere: geographic and phylogenetic variability in the distribution of bacteria on tree leaves. Environ Microbiol. 2010; 12(11): 2885-2893. https://doi.org/10.1111/j.1462-2920.2010.02258.x.

12. Finkel OM, Burch AY, Lindow SE, Post AF, Belkin S. Geographical location determines the population structure in phyllosphere microbial communities of a salt-excreting desert tree. Appl Environ Microbiol. 2011; 77(21): 7647-7655. https://doi.org/10.1128/aem.05565-11.

13. Rastogi G, Coaker GL, Leveau JH. New insights into the structure and function of phyllosphere microbiota through high-throughput molecular approaches. FEMS Microbiol Lett. 2013; 348(1): 1-10. https://doi.org/10.1111/1574-6968.12225.

Page $12 / 28$ 
14. Kembel SW, O'Connor TK, Arnold HK, Hubbell SP, Wright SJ, Green JL. Relationships between phyllosphere bacterial communities and plant functional traits in a neotropical forest. Proc Natl Acad Sci. 2014; 111(38): 13715-13720. https://doi.org/10.1073/pnas.1216057111.

15. Durand A, Maillard F, Alvarez-Lopez V, Guinchard S, Bertheau C, Valot B, et al. Bacterial diversity associated with poplar trees grown on a Hgcontaminated site: Community characterization and isolation of Hg-resistant plant growth-promoting bacteria. Sci Total Environ. 2018 ; $622: 1165-1177$. https://doi.org/10.1016/j.scitotenv.2017.12.069.

16. Kecskeméti E, Berkelmann-Löhnertz B, Reineke A. Are epiphytic microbial communities in the carposphere of ripening grape clusters (Vitis vinifera L.) different between conventional, organic, and biodynamic grapes? PloS one. 2016; 11(8): e0160852. https://doi.org/10.1371/journal.pone.0160852.

17. Aleklett K, Hart M, Shade A. The microbial ecology of flowers: an emerging frontier in phyllosphere research. Botany. 2014; $92(4): 253-266$. https://doi.org/10.1139/cjb-2013-0166.

18. Steven B, Huntley RB, Zeng Q. The influence of flower anatomy and apple cultivar on the apple flower phytobiome. Phytobiomes. 2018;2(3):171-179. https://doi.org/10.1094/pbiomes-03-18-0015-r.

19. Madhaiyan M, Poonguzhali S, Sa TM. Influence of plant species and environmental conditions on epiphytic and endophytic pink-pigmented facultative methylotrophic bacterial populations associated with field-grown rice cultivars. J Microbiol Biotechnol. 2007; 17(10): 1645-1654.

https://doi.org/10.1099/ijs.0.64603-0.

20. Madhaiyan M, Poonguzhali S, Kwon SW, Sa TM. Methylobacterium phyllosphaerae sp. nov., a pink-pigmented, facultative methylotroph from the phyllosphere of rice. Int J Syst Evol Microbiol. 2009; 59(1): 22-27. https://doi.org/10.1099/ijs.0.001693-0.

21. Sivakumar N, Sathishkumar R, Selvakumar G, Shyamkumar R, Arjunekumar K. Phyllospheric Microbiomes: Diversity, Ecological Significance, and Biotechnological Applications. Plant Microbiomes for Sustainable Agriculture: Springer; 2020. p. 113-172. https://doi.org/10.1007/978-3-030-38453-1_5.

22. Schreiber L, Krimm U, Knoll D, Sayed M, Auling G, Kroppenstedt RM. Plant-microbe interactions: identification of epiphytic bacteria and their ability to alter leaf surface permeability. New Phytol. 2005; 166(2): 589-594. https://doi.org/10.1111/j.1469-8137.2005.01343.x.

23. Van der Wal A, Leveau JH. Modelling sugar diffusion across plant leaf cuticles: the effect of free water on substrate availability to phyllosphere bacteria. Environ Microbiol. 2011; 13(3): 792-797. https://doi.org/10.1111/j.1462-2920.2010.02382.x.

24. Dean RA, Talbot NJ, Ebbole DJ, Farman ML, Mitchell TK, Orbach MJ, et al. The genome sequence of the rice blast fungus Magnaporthe grisea. Nature. 2005; 434(7036): 980-986. https://doi.org/10.1038/nature03449.

25. Sharma TR, Rai AK, Gupta SK, Vijayan J, Devanna BN, Ray S. Rice blast management through host-plant resistance: retrospect and prospects. Agric Res. 2012; 1(1): 37-52. https://doi.org/10.1007/s40003-011-0003-5.

26. Yasuda N, Mitsunaga T, Hayashi K, Koizumi S, Fujita Y. Effects of pyramiding quantitative resistance genes pi21, Pi34, and Pi35 on rice leaf blast disease. Plant Dis. 2015; 99(7): 904-909. https://doi.org/10.1094/pdis-02-14-0214-re.

27. Mehta S, Singh B, Dhakate P, Rahman M, Islam MA. Rice, marker-assisted breeding, and disease resistance. Disease Resistance in Crop Plants: Springer; 2019. p. 83-111. https://doi.org/10.1007/978-3-030-20728-1_5.

28. Scheuermann KK, Raimondi JV, Marschalek R, de Andrade A, Wickert E. Magnaporthe oryzae genetic diversity and its outcomes on the search for durable resistance. Mol Basis Plant Genet Divers. 2012: 331-356. https://doi.org/10.5772/33479.

29. Nalley L, Tsiboe F, Durand-Morat A, Shew A, Thoma G. Economic and environmental impact of rice blast pathogen (Magnaporthe oryzae) alleviation in the United States. PloS one. 2016; 11(12): e0167295. https://doi.org/10.1371/journal.pone.0167295.

30. Devi SJSR, Singh K, Umakanth B, Vishalakshi B, Renuka P, Sudhakar KV, et al. Development and identification of novel rice blast resistant sources and their characterization using molecular markers. Rice Science. 2015; 22(6): 300-308. https://doi.org/10.1016/j.rsci.2015.11.002.

31. Gopal M, Gupta A, Thomas GV. Bespoke microbiome therapy to manage plant diseases. Front Microbiol. 2013;4:355. https://doi.org/10.3389/fmicb.2013.00355.

32. Foo JL, Ling H, Lee YS, Chang MW. Microbiome engineering: Current applications and its future. Biotechnol J. 2017; 12 (3): 1600099. https://doi.org/10.1002/biot.201600099.

33. Singh VK, Singh A, Singh SP, Ellur RK, Choudhary V, Sarkel S, et al. Incorporation of blast resistance into "PRR78", an elite Basmati rice restorer line, through marker assisted backcross breeding, Field Crops Res. 2012; 128:8-16. https://doi.org/10.1016/j.fcr.2011.12.003.

34. Moore E, Arnscheidt A, Krüger A, Strömpl C, Mau M. Simplified protocols for the preparation of genomic DNA from bacterial cultures. Molecular microbial ecology manual. 1999; 1(1): 1-15. https://doi.org/10.1007/978-1-4020-2177-0_101.

35. Andrews S. FastQC: a quality control tool for high throughput sequence data. Babraham Bioinformatics, Babraham Institute, Cambridge, United Kingdom. 2018.

36. Bolger AM, Lohse M, Usadel B. Trimmomatic: a flexible trimmer for Illumina sequence data. Bioinformatics. 2014; $30(15): 2114-2120$. https://doi.org/10.1093/bioinformatics/btu170.

37. Dhariwal A, Chong J, Habib S, King IL, Agellon LB, Xia J. MicrobiomeAnalyst: a web-based tool for comprehensive statistical, visual, and meta-analysis of microbiome data. Nucleic Acids Res. 2017; 45(W1): W180-W188. https://doi.org/10.1093/nar/gkx295.

38. Bozzola JJ, Russell LD. Electron microscopy: principles and techniques for biologists. Jones \& Bartlett Learning; 1999. https://doi.org/10.1086/417649.

39. Versalovic J, Schneider M, De Bruijn FJ, Lupski JR. Genomic fingerprinting of bacteria using repetitive sequence-based polymerase chain reaction. Methods Mol Cell Biol. 1994; 5(1): 25-40. https://doi.org/10.1007/978-1-4615-6369-3_34.

40. Kumar A, Sarma YR, Anandaraj M. Evaluation of genetic diversity of Ralstonia solanacearum causing bacterial wilt of ginger using REP-PCR and PCRRFLP. Curr Sci. 2004: 1555-1561. 
41. Eke P, Kumar A, Sahu KP, Wakam LN, Sheoran N, Ashajyothi M, et al. Endophytic bacteria of desert triangular spurge (Euphorbia antiquorumL.) confer drought tolerance and induce growth promotion in tomato (Solanum lycopersicum L.). Microbiol Res. 2019; 228:126302.

https://doi.org/10.1016/j.micres.2019.126302.

42. Sheoran N, Nadakkakath AV, Munjal V, Kundu A, Subaharan K, Venugopal V, et al. Genetic analysis of plant endophytic Pseudomonas putida BP25 and chemo-profiling of its antimicrobial volatile organic compounds. Microbiol Res. 2015; 173:66-78. https://doi.org/10.1016/j.micres.2015.02.001.

43. Munjal V, Nadakkakath AV, Sheoran N, Kundu A, Venugopal V, Subaharan K, et al. Genotyping and identification of broad spectrum antimicrobial volatiles in black pepper root endophytic biocontrol agent, Bacillus megaterium BP17. Biol Control. 2016; 92: 66-76.

https://doi.org/10.1016/j.biocontrol.2015.09.005.

44. Rajashekara H, Ellur RK, Khanna A, Nagarajan M, Gopalakrishnan S, Singh A, et al. Inheritance of blast resistance and its allelic relationship with five major R genes in a rice landrace 'Vanasurya'. Indian Phytopathol. 2014; 67(4): 365-369. https://doi.org/10.5958/0975-6906.2014.00846.3.

45. Mackill D, Bonman J. Inheritance of blast resistance in near-isogenic lines of rice. Phytopathology. 1992; 82(7): 746-749. https://doi.org/10.1094/phyto$82-746$

46. Akamatsu A, Wong HL, Fujiwara M, Okuda J, Nishide K, Uno K, et al. An OsCEBiP/OsCERK1-OsRacGEF1-OsRac1 module is an essential early component of chitin-induced rice immunity. Cell Host Microbe. 2013; 13(4): 465-476. https://doi.org/10.1016/j.chom.2013.03.007.

47. Kouzai Y, Mochizuki S, Nakajima K, Desaki Y, Hayafune M, Miyazaki H, et al. Targeted gene disruption of OsCERK1 reveals its indispensable role in chitin perception and involvement in the peptidoglycan response and immunity in rice. Mol Plant-Microbe Interact. 2014; 27(9): $975-982$.

https://doi.org/10.1094/mpmi-03-14-0068-r.

48. Ke Y, Liu H, Li X, Xiao J, Wang S. Rice OsPAD 4 functions differently from Arabidopsis A t PAD 4 in host-pathogen interactions. The Plant Journal. 2014; 78(4): 619-631. https://doi.org/10.1111/tpj.12500.

49. Ke Y, Kang Y, Wu M, Liu H, Hui S, Zhang Q, et al. Jasmonic acid-involved OsEDS1 signaling in Rice-bacteria interactions. Rice. $2019 ; 12(1): 25$. https://doi.org/10.1186/s12284-019-0283-0.

50. Sugano S, Jiang CJ, Miyazawa SI, Masumoto C, Yazawa K, Hayashi N, et al. Role of OsNPR1 in rice defense program as revealed by genome-wide expression analysis. Plant Mol Biol. 2010;74(6):549-562. https://doi.org/10.1007/s11103-010-9695-3.

51. Thomma BP, Cammue BP, Thevissen K. Plant defensins. Planta. 2002; 216(2): 193-202. https://doi.org/10.1007/s00425-002-0902-6.

52. Mishina TE, Zeier J. The Arabidopsis flavin-dependent mono-oxygenase FMO1 is an essential component of biologically induced systemic acquired resistance. Plant Physiol. 2006; 141(4): 1666-1675. https://doi.org/10.1104/pp.106.081257.

53. Koch M, Vorwerk S, Masur C, Sharifi-Sirchi G, Olivieri N, Schlaich NL. A role for a flavin-containing mono-oxygenase in resistance against microbial pathogens in Arabidopsis. The Plant Journal. 2006; 47(4): 629-639. https://doi.org/10.1111/j.1365-313x.2006.02813.x.

54. Breen S, Williams SJ, Outram M, Kobe B, Solomon PS. Emerging insights into the functions of pathogenesis-related protein 1. Trends Plant Sci. 2017; 22(10): 871-879. https://doi.org/10.1016/j.tplants.2017.06.013.

55. Brader G, Compant S, Vescio K, Mitter B, Trognitz F, Ma LJ, et al. Ecology and genomic insights into plant-pathogenic and plant-nonpathogenic endophytes. Annu Rev Phytopathol. 2017; 55: 61-83. https://doi.org/10.1146/annurev-phyto-080516-035641.

56. Lemanceau P, Blouin M, Muller D, Moënne-Loccoz Y. Let the core microbiota be functional. Trends Plant Sci. 2017; 22(7): 583-595. https://doi.org/10.1016/j.tplants.2017.04.008.

57. Reinhold-Hurek B, Bünger W, Burbano CS, Sabale M, Hurek T. Roots shaping their microbiome: global hotspots for microbial activity. Annu Rev Phytopathol. 2015; 53: 403-424. https://doi.org/10.1146/annurev-phyto-082712-102342.

58. Hardoim PR, Van Overbeek LS, Berg G, Pirttilä AM, Compant S, Campisano A, et al. The hidden world within plants: ecological and evolutionary considerations for defining functioning of microbial endophytes. Microbiol Mol Biol Rev. 2015; 79(3): 293-320. https://doi.org/10.1128/mmbr.00050-14.

59. Mills LS, Soulé ME, Doak DF. The keystone-species concept in ecology and conservation. BioScience. 1993;43(4):219-224. https://doi.org/10.2307/1312122.

60. Toju H, Peay KG, Yamamichi M, Narisawa K, Hiruma K, Naito K, et al. Core microbiomes for sustainable agroecosystems. Nat Plants. 2018;4(5):247-257. https://doi.org/10.1038/s41477-018-0139-4.

61. Jacobs JL, Carroll TL, Sundin GW. The role of pigmentation, ultraviolet radiation tolerance, and leaf colonization strategies in the epiphytic survival of phyllosphere bacteria. Microb Ecol. 2005; 49(1): 104-113. https://doi.org/10.1007/s00248-003-1061-4.

62. Stone BW, Jackson CR. Seasonal Patterns Contribute More Towards Phyllosphere Bacterial Community Structure than Short-Term Perturbations, Microb Ecol. 2020:1-11. https://doi.org/10.1007/s00248-020-01564-z.

63. Li WT, Chern MS, Yin JJ, Wang J, Chen Xw. Recent advances in broad-spectrum resistance to the rice blast disease. Curr Opin Plant Biol. 2019; 50: 114120. https://doi.org/10.1016/j.pbi.2019.03.015.

64. Yasmin S, Hakim S, Zaheer A, Mirza B, Mirza MS. Metagenomic Analysis of Bacterial Community Associated with Rhizosphere and Phyllosphere of Basmati Rice. bioRxiv. 2020. https://doi.org/10.1101/2020.04.09.034009.

65. Ren G, Zhang H, Lin X, Zhu J, Jia Z. Response of phyllosphere bacterial communities to elevated $\mathrm{CO}_{2}$ during rice growing season. Appl Microbiol Biotechnol. 2014; 98(22): 9459-9471. https://doi.org/10.1007/s00253-014-5915-0.

66. Knief C, Delmotte N, Chaffron S, Stark M, Innerebner G, Wassmann R, et al. Metaproteogenomic analysis of microbial communities in the phyllosphere and rhizosphere of rice. The ISME journal. 2012; 6(7): 1378-1390. https://doi.org/10.1038/ismej.2011.192. 
67. Roman-Reyna V, Pinili D, Borjaa FN, Quibod I, Groen SC, Mulyaningsih ES, et al. The rice leaf microbiome has a conserved community structure controlled by complex host-microbe interactions. Cell-Host-Microbe-D-19-00340. 2019. https://doi.org/10.2139/ssrn.3382544.

68. Midha S, Bansal K, Sharma S, Kumar N, Patil PP, Chaudhry V, et al. Genomic resource of rice seed associated bacteria. Front in Microbiol. $2016 ; 6: 1551$. https://doi.org/10.3389/fmicb.2015.01551.

69. Eyre AW, Wang M, Oh Y, Dean RA. Identification and characterization of the core rice seed microbiome. Phytobiomes Journal. $2019 ; 3(2): 148-157$. https://doi.org/10.1094/pbiomes-01-19-0009-r.

70. Kim H, Lee KK, Jeon J, Harris WA, Lee YH. Domestication of Oryza species eco-evolutionarily shapes bacterial and fungal communities in rice seed. Microbiome. 2020; 8(1): 1-17. https://doi.org/10.1186/s40168-020-00805-0.

71. Edwards J, Johnson C, Santos-Medellín C, Lurie E, Podishetty NK, Bhatnagar S, et al. Structure, variation, and assembly of the root-associated microbiomes of rice. Proc Natl Acad Sci. 2015; 112(8): E911-E920. https://doi.org/10.1073/pnas.1414592112.

72. Xu J, Zhang J, Zhu C, Zhu J, Lin X, Feng Y. Influence of rice cultivars on soil bacterial microbiome under elevated carbon dioxide. J Soils Sed. 2019; 19(5): 2485-2495. https://doi.org/10.1007/s11368-018-2220-z.

73. Simonin M, Dasilva C, Terzi V, Ngonkeu EL, Diouf D, Kane A, et al. Influence of plant genotype and soil on the wheat rhizosphere microbiome: Evidences for a core microbiome across eight African and European soils. FEMS Microbiol Ecol. 2020; 96(6): fiaa067. https://doi.org/10.1093/femsec/fiaa067.

74. Brusetti L, Malkhazova I, Gtari M, Tamagnini I, Borin S, Merabishvili M, et al. Fluorescent-BOX-PCR for resolving bacterial genetic diversity, endemism and biogeography. BMC Microbiol. 2008; 8(1): 1-13. https://doi.org/10.1186/1471-2180-8-220.

75. Charishma K. Comparative analysis of spermosphere and phyllosphere bacteriome of rice and their effect on foliar pathogens, Magnaporthe oryzae and Xanthomonas oryzae pv. oryzae: Division of Plant Pathology ICAR-Indian Agricultural Research Institute New Delhi. https://krishikosh.egranth.ac.in/handle/1/5810143449.

76. Green PN. The genus Methylobacterium. The prokaryotes. 1992. https://doi.org/10.1007/0-387-30745-1_14.

77. Lewis FG, Antony MG. Melanin and novel melanin precursors from Aeromonas media. FEMS Microbiol Lett. 1998; 169: $261-268$. https://doi.org/10.1111/j.1574-6968.1998.tb13327.x.

78. Carvalho SD, Castillo JA. Influence of light on plant-phyllosphere interaction. Front Plant Sci. 2018;9:1482. https://doi.org/10.3389/fpls.2018.01482.

79. Cottyn B, Debode J, Regalado E, Mew TW, Swings J. Phenotypic and genetic diversity of rice seed-associated bacteria and their role in pathogenicity and biological control. J Appl Microbiol. 2009; 107(3): 885-897. https://doi.org/10.1111/j.1365-2672.2009.04268.x.

80. Cother EJ, Noble DH, Van De Ven RJ, Lanoiselet V, Ash G, Vuthy N, et al. Bacterial pathogens of rice in the Kingdom of Cambodia and description of a new pathogen causing a serious sheath rot disease. Plant Pathol. 2010; 59(5): 944-953. https://doi.org/10.1111/j.1365-3059.2010.02310.x.

81. Morohoshi T, Wang WZ, Someya N, Ikeda T. Genome sequence of Microbacterium testaceum StLB037, an N-acylhomoserine lactone-degrading bacterium isolated from potato leaves. Am Soc Microbiol; 2011; 2072-2073. https://doi.org/10.1128/jb.00180-11.

82. Leveau JH, Lindow SE. Appetite of an epiphyte: quantitative monitoring of bacterial sugar consumption in the phyllosphere. Proc Natl Acad Sci. 2001; 98(6): 3446-3453. https://doi.org/10.1073/pnas.061629598.

83. Kaku H, Subandiyah S, Ochiai H. Red stripe of rice [Oryza sativa] is caused by a bacterium Microbacterium sp. J Gen Plant Pathol (Japan). 2000. https://doi.org/10.1007/pl00012937.

84. Favia G, Ricci I, Marzorati M, Negri I, Alma A, Sacchi L, et al. Bacteria of the genus Asaia: a potential paratransgenic weapon against malaria. Transgenesis and the management of vector-borne disease: Springer; 2008. p. 49-59. https://doi.org/10.1007/978-0-387-78225-6_4.

85. Morris CE, Monier J, Jacques M. Methods for observing microbial biofilms directly on leaf surfaces and recovering them for isolation of culturable microorganisms, Appl Environ Microbiol. 1997;63(4):1570-1576. https://doi.org/10.1128/aem.63.4.1570-1576.1997.

86. Remus-Emsermann MN, Lücker S, Müller DB, Potthoff E, Daims H, Vorholt JA. Spatial distribution analyses of natural phyllosphere-colonizing bacteria on A rabidopsis thaliana revealed by fluorescence in situ hybridization, Environ Microbiol. 2014;16(7):2329-2340. https://doi.org/10.1111/14622920.12482.

87. Monier JM, Lindow S. Frequency, size, and localization of bacterial aggregates on bean leaf surfaces, Appl Environ Microbiol. 2004;70(1):346-355. https://doi.org/10.1128/aem.70.1.346-355.2004.

88. Liu CH, Chen X, Liu TT, Lian B, Gu Y, Caer V, et al. Study of the antifungal activity of Acinetobacter baumannii LCH001 in vitro and identification of its antifungal components. Appl Microbiol Biotechnol. 2007; 76(2): 459-466. https://doi.org/10.1007/s00253-007-1010-0.

89. Gasser F, Cardinale M, Schildberger B, Berg G. Biocontrol of Botrytis cinerea by successful introduction of Pantoea ananatis in the grapevine phyllosphere. Int J Wine Res. 2012; 4: 53-63. https://doi.org/10.2147/ijwr.s31339.

90. Sadik S, Mazouz H, Benbouazza ABA, Achbani E. Biological control of bacterial onion diseases using a bacterium, Pantoeaagglomerans 2066-7. Int J Sci Res. 2015; 4(1): 103-111. https://doi.org/10.15414/jmbfs.2016.5.6.612-616.

91. Horuz S, Aysan Y. Biological control of watermelon seedling blight caused by Acidovorax citrulli using antagonistic bacteria from the genera Curtobacterium, Microbacterium, and Pseudomonas. Plant Prot Sci. 2018; 54(3): 138-146. https://doi.org/10.17221/168/2016-pps.

92. Rariz G, Ferrando L, Echegoyen N, Scavino AF. Antagonism between Azospirillumbrasilense Az39 and Pseudomonas oryzihabitans, a seed-borne endophyte, in growing rice plants. Rev Agronómica del Noroeste Argentino. 2017;31:45-56.

93. Vagelas I, Gowen SR. Control of Fusarium oxysporum and root-knot nematodes (Meloidogyne spp.) with Pseudomonas oryzihabitans. Pak J Phytopathol. 2012; 24(1): 32-38. 
94. Ashajyothi M, Kumar A, Sheoran N, Ganesan P, Gogoi R, Subbaiyan GK, et al. Black pepper (Piper nigrum L.) associated endophytic Pseudomonas putida BP25 alters root phenotype and induces defense in rice (Oryza sativa L.) against blast disease incited by Magnaporthe oryzae. Biol Control. 2020; 143 : 104181. https://doi.org/10.1016/j.biocontrol.2019.104181.

95. Gómez Expósito R, De Bruijn I, Postma J, Raaijmakers JM. Current insights into the role of rhizosphere bacteria in disease suppressive soils. Front Microbiol. 2017; 8: 2529. https://doi.org/10.3389/fmicb.2017.02529.

96. Schlatter D, Kinkel L, Thomashow L, Weller D, Paulitz T. Disease suppressive soils: new insights from the soil microbiome. Phytopathology. 2017; 107(11): 1284-1297. https://doi.org/10.1094/phyto-03-17-0111-rvw.

97. Harsonowati W, Astuti RI, Wahyudi AT. Leaf blast disease reduction by rice-phyllosphere actinomycetes producing bioactive compounds. J Gen Plant Pathol. 2017; 83(2): 98-108. https://doi.org/10.1007/s10327-017-0700-4.

98. Hasegawa M, Mitsuhara I, Seo S, Imai T, Koga J, Okada K, et al. Phytoalexin accumulation in the interaction between rice and the blast fungus. Mol PlantMicrobe Interact. 2010; 23(8): 1000-1011. https://doi.org/10.1094/mpmi-23-8-1000.

99. Sheoran N, Kumar A, Munjal V, Nadakkakath AV, Eapen SJ. Pseudomonas putida BP25 alters root phenotype and triggers salicylic acid signaling as a feedback loop in regulating endophytic colonization in Arabidopsis thaliana. Physiol Mol Plant Pathol. 2016; 93:99-111.

https://doi.org/10.1016/j.pmpp.2016.01.008.

100. Munjal V, Kumar A, Sheoran N, Nadakkakath AV, Eapen SJ. Molecular basis of endophytic Bacillus megaterium-induced growth promotion in Arabidopsis thaliana: revelation by microarray-based gene expression analysis. J Plant Growth Regul. 2017; 36(1): 118-130. https://doi.org/10.1007/s00344-0169624-z.

101. Sahu KP, Kumar A, Patel A, Kumar M, Gopalakrishnan S, Prakash G, et al. Rice Blast Lesions: an Unexplored Phyllosphere Microhabitat for Novel Antagonistic Bacterial Species Against Magnaporthe oryzae. Microb Ecol. 2020: 1-15. https://doi.org/10.1007/s00248-020-01617-3.

102. Patel A, Kumar A, Sheoran N, Kumar M, Sahu KP, Ganeshan P, et al. Antifungal and defense elicitor activities of pyrazines identified in endophytic Pseudomonas putida BP25 against fungal blast incited by Magnaporthe oryzae in rice. J Plant Dis Protect. 2020: 1-12. https://doi.org/10.1007/s41348020-00373-3.

\section{Tables}

Table 1. a-diversity of rice phyllomicrobiome representing contrasting agroclimatic zones

\begin{tabular}{|c|c|c|c|c|c|c|c|c|c|c|}
\hline \multirow[t]{2}{*}{ Location } & \multirow[t]{2}{*}{ Genotype } & \multirow[t]{2}{*}{ Samples } & \multicolumn{2}{|c|}{ Shannon } & \multicolumn{2}{|l|}{ Chao1 } & \multicolumn{2}{|c|}{ Simpson } & \multicolumn{2}{|c|}{ Observed } \\
\hline & & & Value & & Value & SE & Value & SE & Value & SE \\
\hline Island Zone & PRR78 & PRR78-ANI1-R1 & 2.615 & - & 274.65 & 34.14 & 0.875 & - & 177 & - \\
\hline Island Zone & PRR78 & PRR78-ANI1-R2 & 2.979 & - & 284.00 & 15.95 & 0.896 & - & 239 & - \\
\hline Mountain Zone & PRR78 & PRR78-PIm1-R1 & 2.120 & - & 128.11 & 8.86 & 0.783 & - & 111 & - \\
\hline Mountain Zone & PRR78 & PRR78-PIm2-R2 & 2.356 & - & 195.83 & 19.78 & 0.767 & - & 148 & - \\
\hline Island Zone & Pusa1602 & Pusa1602-ANI1-R1 & 2.178 & - & 263.09 & 22.43 & 0.729 & - & 194 & - \\
\hline Island Zone & Pusa1602 & Pusa1602-ANI2-R2 & 2.784 & - & 265.88 & 11.74 & 0.843 & - & 234 & - \\
\hline Mountain Zone & Pusa1602 & Pusa1602-PIm1-R1 & 2.527 & - & 205.24 & 10.36 & 0.815 & - & 181 & - \\
\hline Mountain Zone & Pusa1602 & Pusa1602-PIm2-R2 & 3.154 & - & 300.61 & 12.14 & 0.881 & - & 267 & - \\
\hline
\end{tabular}

Microbiome Analyst [37] was utilized for the determination of a-diversity

Table 2. Genotype or climate zone-specific and common bacterial communities associated with phyllosphere of rice 


\begin{tabular}{|c|c|c|c|c|c|c|c|}
\hline $\begin{array}{l}\text { Blast Susceptible } \\
\text { (PRR78) }\end{array}$ & Prevalence & $\begin{array}{l}\text { Blast resistant } \\
\text { (Pusa1602) }\end{array}$ & Prevalence & $\begin{array}{l}\text { Mountain zone } \\
\text { (Palampur) }\end{array}$ & Prevalence & $\begin{array}{l}\text { Island zone } \\
\text { (Port Blair) }\end{array}$ & Prevalence \\
\hline- & - & Acidovorax & 0.5 & Acidovorax & 1 & - & - \\
\hline Arthrobacter & 0.5 & Arthrobacter & 0.5 & Arthrobacter & 1 & - & - \\
\hline Bacillus & 0.5 & Bacillus & 0.75 & Bacillus & 1 & Bacillus & 1 \\
\hline Clavibacter & 0.25 & Clavibacter & 0.25 & - & - & Clavibacter & 0.5 \\
\hline- & - & Clostridium & 0.25 & - & - & Clostridium & 0.25 \\
\hline - & - & Cronobacter & 0.5 & Cronobacter & 1 & Cronobacter & 0.25 \\
\hline Curtobacterium & 0.75 & Curtobacterium & 0.75 & Curtobacterium & 1 & Curtobacterium & 1 \\
\hline Deinococcus & 0.25 & Deinococcus & 0.5 & Deinococcus & 0.5 & Deinococcus & 0.5 \\
\hline Erwinia & 0.25 & Erwinia & 0.25 & Erwinia & 0.5 & - & - \\
\hline Exiguobacterium & 1 & Exiguobacterium & 1 & Exiguobacterium & 0.5 & Exiguobacterium & 1 \\
\hline Hymenobacter & 0.25 & Hymenobacter & 0.5 & Hymenobacter & 0.5 & Hymenobacter & 0.5 \\
\hline- & - & Kineococcus & 0.5 & Kineococcus & 0.5 & Kineococcus & 0.25 \\
\hline Klebsiella & 1 & - & - & Klebsiella & 0.5 & Klebsiella & 0.5 \\
\hline Methylobacterium & 0.5 & Methylobacterium & 1 & Methylobacterium & 0.5 & Methylobacterium & 1 \\
\hline Methylocella & 0.25 & - & - & - & - & Methylocella & 0.25 \\
\hline Microbacterium & 0.5 & Microbacterium & 0.75 & Microbacterium & 0.5 & Microbacterium & 0.25 \\
\hline- & - & Nocardioides & 0.5 & Nocardioides & 0.25 & - & - \\
\hline Pantoea & 1 & Pantoea & 1 & Pantoea & 0.25 & Pantoea & 1 \\
\hline Pedobacter & 0.25 & - & - & Pedobacter & 0.25 & - & - \\
\hline Pseudomonas & 0.5 & - & - & Pseudomonas & 0.25 & - & - \\
\hline- & - & Salmonella & 0.25 & Salmonella & 0.25 & - & - \\
\hline - & - & Serratia & 0.25 & Serratia & 0.25 & - & - \\
\hline Sphingomonas & 0.75 & Sphingomonas & 0.5 & Sphingomonas & 0.25 & Sphingomonas & 0.75 \\
\hline Streptomyces & 0.25 & - & - & - & - & Streptomyces & 0.25 \\
\hline
\end{tabular}

Red: Blast susceptible genotype-specific bacterial genera

Navy Blue: Blast resistant genotype-specific bacterial genera

Green: Mountain zone-specific bacterial genera

Dark blue: Island zone-specific bacterial genera

Black: Common bacterial genera

Table 3. Core phyllomicrobiome of rice genotypes grown in two contrasting climate zones 


\begin{tabular}{|ll|}
\hline Core phyllomicrobiome & Prevalence \\
\hline Acidovorax & 0.25 \\
\hline Arthrobacter & 0.5 \\
\hline Bacillus & 0.625 \\
\hline Clavibacter & 0.25 \\
\hline Clostridium & 0.125 \\
\hline Cronobacter & 0.25 \\
\hline Curtobacterium & 0.75 \\
\hline Deinococcus & 0.375 \\
\hline Erwinia & 0.25 \\
\hline Exiguobacterium & 1.0 \\
\hline Hymenobacter & 0.375 \\
\hline Kineococcus & 0.25 \\
\hline Klebsiella & 0.5 \\
\hline Methylobacterium & 0.75 \\
\hline Methylocella & 0.125 \\
\hline Microbacterium & 0.625 \\
\hline Nocardioides & 0.25 \\
\hline Pantoea & 1.0 \\
\hline Pedobacter & 0.125 \\
\hline Pseudomonas & 0.25 \\
\hline Salmonella & 0.125 \\
\hline Serratia & 0.125 \\
\hline Sphingomonas & 0.625 \\
\hline Streptomyces & 0.125 \\
\hline
\end{tabular}

Microbiome Analyst [37] was utilized for the determination of core phyllomicrobiome

Table 4. Diversity indices of cultured-phyllosphere bacterial communities representing three geographical locations

\begin{tabular}{|c|c|c|c|c|c|}
\hline \multirow[t]{3}{*}{ Rice phyllosphere } & \multirow[t]{3}{*}{ Parameters } & \multicolumn{4}{|c|}{ *Age of plantlets } \\
\hline & & \multicolumn{2}{|l|}{15} & \multicolumn{2}{|l|}{30} \\
\hline & & Pusa1602 & PRR78 & Pusa1602 & PRR78 \\
\hline \multirow[t]{2}{*}{ Palampur } & Shannon Wiener diversity index & 1.30 & 1.80 & 1.80 & 1.58 \\
\hline & Species richness & 10.0 & 10.0 & 15.0 & 17.0 \\
\hline \multirow[b]{2}{*}{ Port Blair } & Shannon Wiener diversity index & 1.12 & 1.40 & 1.40 & 1.34 \\
\hline & Species richness & 12.0 & 9.0 & 17.0 & 17.0 \\
\hline
\end{tabular}

* Days Post Transplanting

Table 5. Antifungal antagonistic activity displayed by bacterial communities associated with phyllomicrobiome on Magnaporthe oryzae 


\begin{tabular}{|c|c|c|c|c|c|c|}
\hline \multirow[t]{2}{*}{ Genus } & \multirow{2}{*}{$\begin{array}{l}\text { Bacterial isolate } \\
\left({ }^{\star} \text { Closet Match) }\right.\end{array}$} & \multirow{2}{*}{$\begin{array}{l}\text { *Sequence } \\
\text { length } \\
\text { (bp) }\end{array}$} & \multirow[t]{2}{*}{$\begin{array}{l}\text { *GenBank } \\
\text { Accession }\end{array}$} & \multirow[t]{2}{*}{$\begin{array}{l}\text { Geographical } \\
\text { Zone }\end{array}$} & \multicolumn{2}{|c|}{$\begin{array}{l}\text { Mycelial Inhibition } \\
(\%)\end{array}$} \\
\hline & & & & & BVC & SC \\
\hline \multirow[t]{3}{*}{ Acidovorax } & Acidovorax avenae OsEp-PIm-30P1 & 1433 & MT367817 & Mountain zone & 34.3 & 3.7 \\
\hline & Acidovorax avenae OsEp-PIm-30P23 & 1378 & MT367833 & Mountain zone & 27.9 & 12.0 \\
\hline & Acidovorax avenae 0sEp-PIm-30P6 & 1396 & MT367820 & Mountain zone & 29.3 & 4.6 \\
\hline \multirow[t]{6}{*}{ Acinetobacter } & Acinetobacter baumannii OsEp-PIm-30P11 & 1430 & MT367824 & Mountain zone & 100.0 & 39.8 \\
\hline & Acinetobacter baumannii OsEp-PIm-30P17 & 1401 & MT367827 & Mountain zone & 100.0 & 50.9 \\
\hline & Acinetobacter junii OsEp-AN-30A17 & 1386 & МT367859 & Island zone & 52.9 & 7.4 \\
\hline & Acinetobacter soli OsEp-PIm-30P2 & 1419 & MT394056 & Mountain zone & 32.9 & 39.8 \\
\hline & Acinetobacter soli OsEp-PIm-30P4 & 1429 & MT367819 & Mountain zone & 100.0 & 42.6 \\
\hline & Acinetobacter soliOsEp-PIm-30P22 & 1417 & MT367832 & Mountain zone & 32.1 & 34.3 \\
\hline Agrobacterium & Agrobacterium larrymoorei OsEp-PIm-30P19 & 1359 & MT367829 & Mountain zone & 46.4 & 5.6 \\
\hline \multirow[t]{2}{*}{ Aureimonas } & Aureimonas phyllosphaerae OsEp-AN-30A11 & 1390 & MT367855 & Island zone & 33.6 & 6.5 \\
\hline & Aureimonas sp.0sEp-PIm-30P7 & 1369 & МT367821 & Mountain zone & 100.0 & 4.6 \\
\hline \multirow[t]{5}{*}{ Curtobacterium } & Curtobacterium albidum OsEp-PIm-15P1 & 1391 & MT367807 & Mountain zone & 32.1 & 1.9 \\
\hline & Curtobacterium albidum OsEp-PIm-30P20 & 1401 & MT367830 & Mountain zone & 57.9 & 7.4 \\
\hline & Curtobacterium citreum 0 sEp-AN-30A1 & 1395 & MT367846 & Island zone & 40.0 & 10.2 \\
\hline & Curtobacterium luteum OsEp-PIm-30P9 & 1393 & MT367822 & Mountain zone & 39.3 & 13.9 \\
\hline & Curtobacterium luteum OsEp-PIm-15P7 & 1390 & MT367812 & Mountain zone & 60.0 & 4.6 \\
\hline \multirow[t]{6}{*}{ Enterobacter } & Enterobacter asburiae OsEp-AN-30A22 & 1406 & MT367864 & Island zone & 23.6 & 6.5 \\
\hline & Enterobacter asburiae OsEp-PIm-30P16 & 1410 & MT367826 & Mountain zone & 41.4 & 35.2 \\
\hline & Enterobacter cloacae OsEp-AN-15A7 & 1409 & MT367840 & Island zone & 0.0 & 7.4 \\
\hline & Enterobacter cloacae OsEp-PIm-30P18 & 1425 & MT367828 & Mountain zone & 18.6 & 23.2 \\
\hline & Enterobacter mori OsEp-AN-30A20 & 1409 & MT367862 & Island zone & 25.7 & 9.3 \\
\hline & Enterobacter sichuanensis OsEp-AN-15A12 & 1404 & MT367844 & Island zone & 41.4 & 5.6 \\
\hline Erwinia & Erwinia tasmaniensis OsEp-AN-15A5 & 1412 & MT367838 & Island zone & 56.4 & 54.6 \\
\hline \multirow[t]{4}{*}{ Exiguobacterium } & Exiguobacterium acetylicum 0sEp-PIm-15P3 & 1438 & МT367809 & Mountain zone & 54.3 & 1.9 \\
\hline & Exiguobacterium indicum OsEp-AN-30A4 & 1413 & MT367849 & Island zone & 63.6 & 46.3 \\
\hline & Exiguobacterium indicum OsEp-AN-30A6 & 1430 & MT367851 & Island zone & 32.1 & 14.8 \\
\hline & Exiguobacterium indicum 0sEp-PIm-30P14 & 1431 & MT367825 & Mountain zone & 24.3 & 3.7 \\
\hline \multirow[t]{2}{*}{ Microbacterium } & Microbacterium sp. OsEp-AN-15A2 & 1387 & MT367835 & Island zone & 0.0 & 13.9 \\
\hline & Microbacterium testaceum OsEp-AN-30A2 & 1409 & MT367847 & Island zone & 47.1 & 38.9 \\
\hline Micrococcus & Micrococcus luteus OsEp-AN-15A1 & 1400 & MT367834 & Island zone & 0.0 & 12.0 \\
\hline \multirow[t]{10}{*}{ Pantoea } & Pantoea agglomerans OsEp-AN-15A8 & 1418 & MT367841 & Island zone & 69.3 & 7.4 \\
\hline & Pantoea agglomerans OsEp-AN-30A14 & 1408 & MT367857 & Island zone & 100.0 & 42.6 \\
\hline & Pantoea agglomerans OsEp-AN-30A21 & 1413 & МТ367863 & Island zone & 40.0 & 10.2 \\
\hline & Pantoea ananatis OsEp-AN-15A10 & 1401 & МT367843 & Island zone & 81.4 & 50.0 \\
\hline & Pantoea ananatis OsEp-AN-30A19 & 1408 & МT367861 & Island zone & 30.7 & 7.4 \\
\hline & Pantoea ananatis OsEp-AN-30A5 & 1402 & MT367850 & Island zone & 100.0 & 4.6 \\
\hline & Pantoea ananatis OsEp-AN-30A8 & 1403 & MT367852 & Island zone & 100.0 & 7.4 \\
\hline & Pantoea ananatis OsEp-PIm-15P9 & 1410 & MT367813 & Mountain zone & 100.0 & 34.3 \\
\hline & Pantoea ananatis OsEp-PIm-30P21 & 1405 & МT367831 & Mountain zone & 100.0 & 50.0 \\
\hline & Pantoea ananatis OsEp-PIm-30P3 & 1419 & МT367818 & Mountain zone & 74.3 & 50.0 \\
\hline
\end{tabular}

Page 19/28 


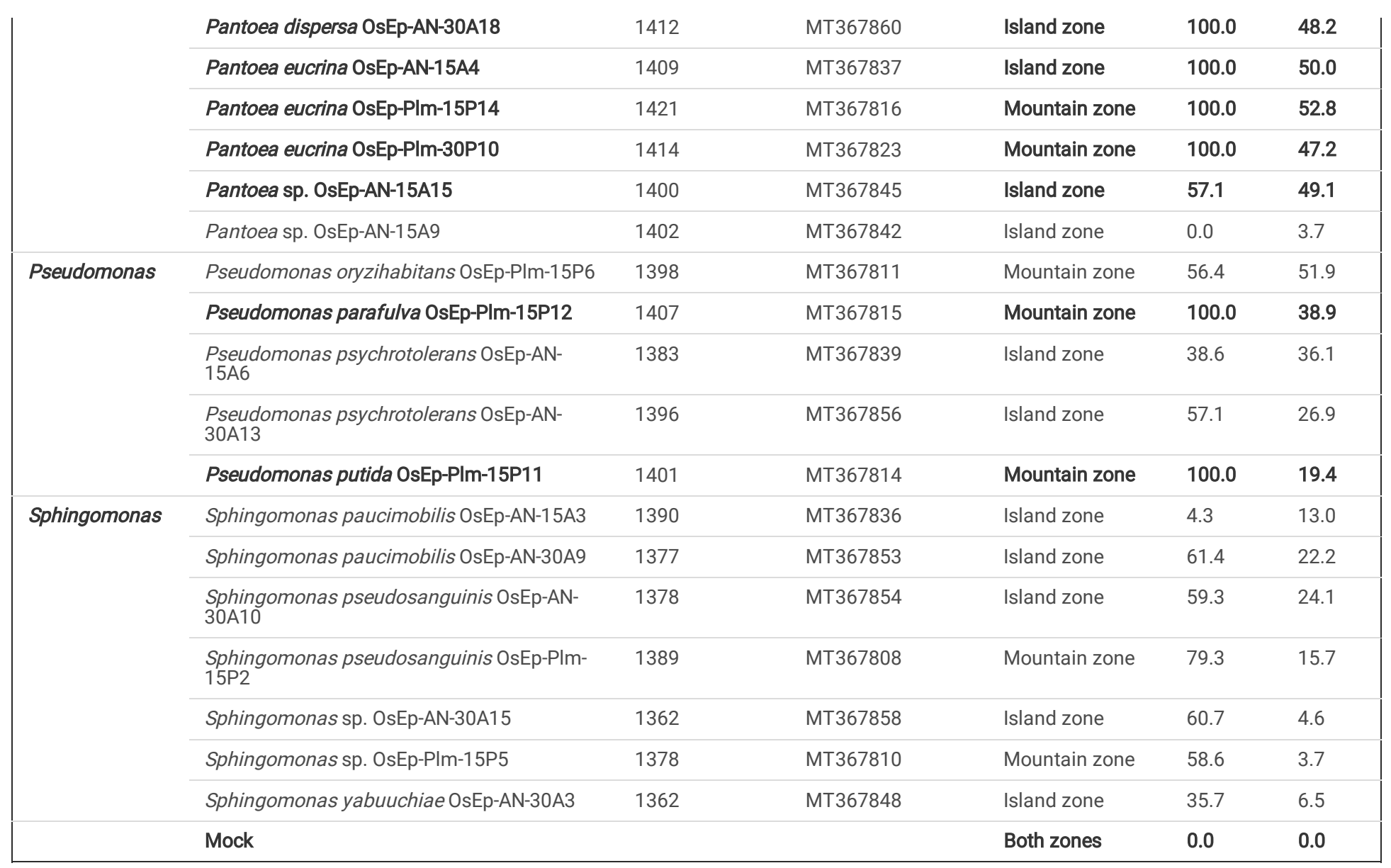

*16S rRNA gene sequences as accessed in https://blast.ncbi.nlm.nih.gov/Blast.cgi during December 2020

Table 6. Blast suppressive potential showed by phyllosphere bacterial genera on rice 


\begin{tabular}{|c|c|c|c|}
\hline \multirow[t]{2}{*}{ Genus } & \multirow[t]{2}{*}{ Bacterial isolates } & \multicolumn{2}{|c|}{ *Blast disease suppression } \\
\hline & & *Severity Score & *Severity Reduction (\%) \\
\hline \multirow[t]{3}{*}{ Acinetobacter } & Acinetobacter baumannii OsEp-PIm-30P11 & 26.8 & 47.3 \\
\hline & Acinetobacter baumannii OsEp-PIm-30P17 & 28.6 & 43.7 \\
\hline & Acinetobacter soli OsEp-PIm-30P4 & 33.3 & 34.5 \\
\hline Aureimonas & Aureimonas sp. OsEp-PIm-30P7 & 13.7 & 73.0 \\
\hline Erwinia & Erwinia tasmaniensis OsEp-AN-15A5 & 33.5 & 34.2 \\
\hline Exiguobacterium & Exiguobacterium indicum OsEp-AN-30A4 & 33.0 & 35.0 \\
\hline \multirow[t]{12}{*}{ Pantoea } & Pantoea agglomerans OsEp-AN-30A14 & 29.7 & 41.5 \\
\hline & Pantoea ananatis OsEp-PIm-30P3 & 13.1 & 74.3 \\
\hline & Pantoea ananatis OsEp-PIm-30P21 & 13.1 & 74.2 \\
\hline & Pantoea ananatis OsEp-AN-30A8 & 13.7 & 73.0 \\
\hline & Pantoea ananatis OsEp-PIm-15P9 & 25.6 & 49.7 \\
\hline & Pantoea ananatis OsEp-AN-15A10 & 27.2 & 46.6 \\
\hline & Pantoea ananatis OsEp-AN-30A5 & 30.4 & 40.2 \\
\hline & Pantoea dispersa OsEp-AN-30A18 & 31.2 & 38.5 \\
\hline & Pantoea eucrina OsEp-PIm-30P10 & 14.5 & 71.5 \\
\hline & Pantoea eucrina OsEp-AN-15A4 & 27.1 & 46.7 \\
\hline & Pantoea eucrina OsEp-PIm-15P14 & 28.0 & 45.0 \\
\hline & Pantoea sp. OsEp-AN-15A15 & 27.2 & 46.5 \\
\hline \multirow[t]{2}{*}{ Pseudomonas } & Pseudomonas parafulva OsEp-PIm-15P12 & 32.5 & 36.2 \\
\hline & Pseudomonas putida OsEp-PIm-15P11 & 24.5 & 51.8 \\
\hline Pathogen-Check & Control & 50.8 & 0.0 \\
\hline Fungicide-Check & Tricyclazole control & 8.33 & 83.6 \\
\hline
\end{tabular}

*Average of three repeat trials each with five replications

\section{Figures}




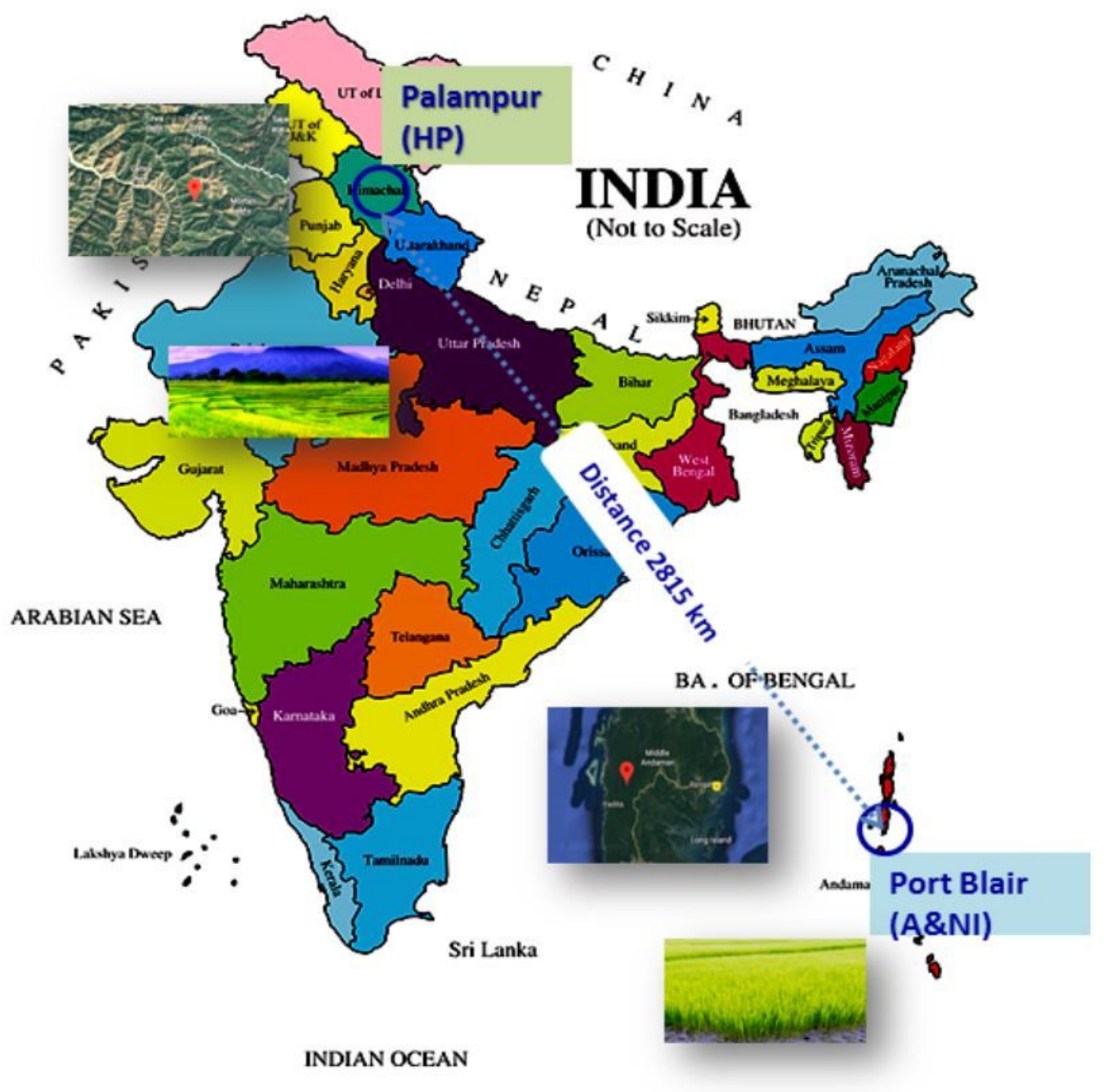

Figure 1

Experimental site at Mountain agroclimatic zone and Island agroclimatic zone of India. Satellite images of experimental sites, Palampur in Himachal Pradesh, India, and Port Blair, Andaman \& Nicobar Island are shown inserted. Experiments were conducted during the rice cultivation season in the two locations. Note: The designations employed and the presentation of the material on this map do not imply the expression of any opinion whatsoever on the part of Research Square concerning the legal status of any country, territory, city or area or of its authorities, or concerning the delimitation of its frontiers or boundaries. This map has been provided by the authors. 
A

B
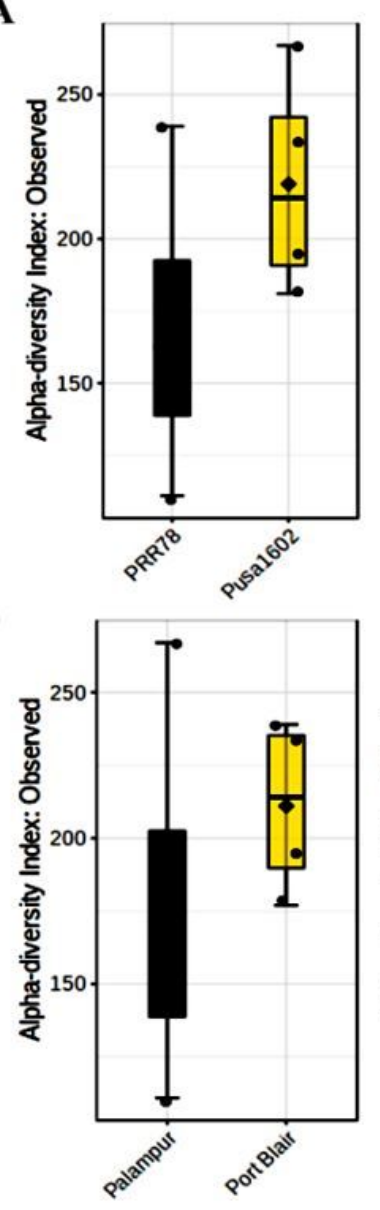
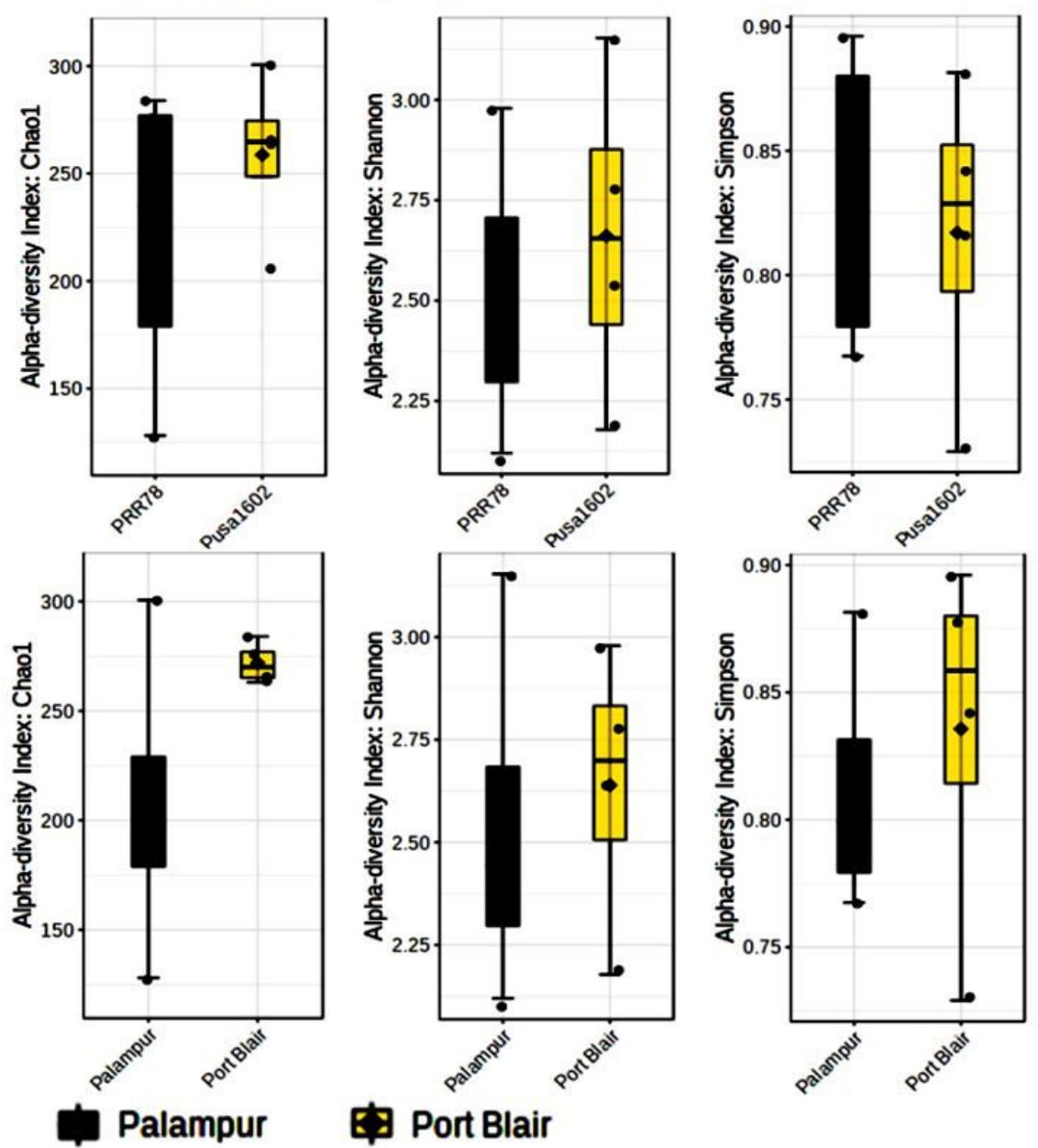

Figure 2

Alpha diversity Indices of rice phyllomicrobiome; Comparative diversity indices for, (A) Two genotypes i.e. PRR 78 -a blast disease susceptible genotype, and Pusa 1602 -a blast disease-resistant NIL genotype; (B) Two locations i.e. Palampur - Mountain zone and Port Blair - Island zone

A

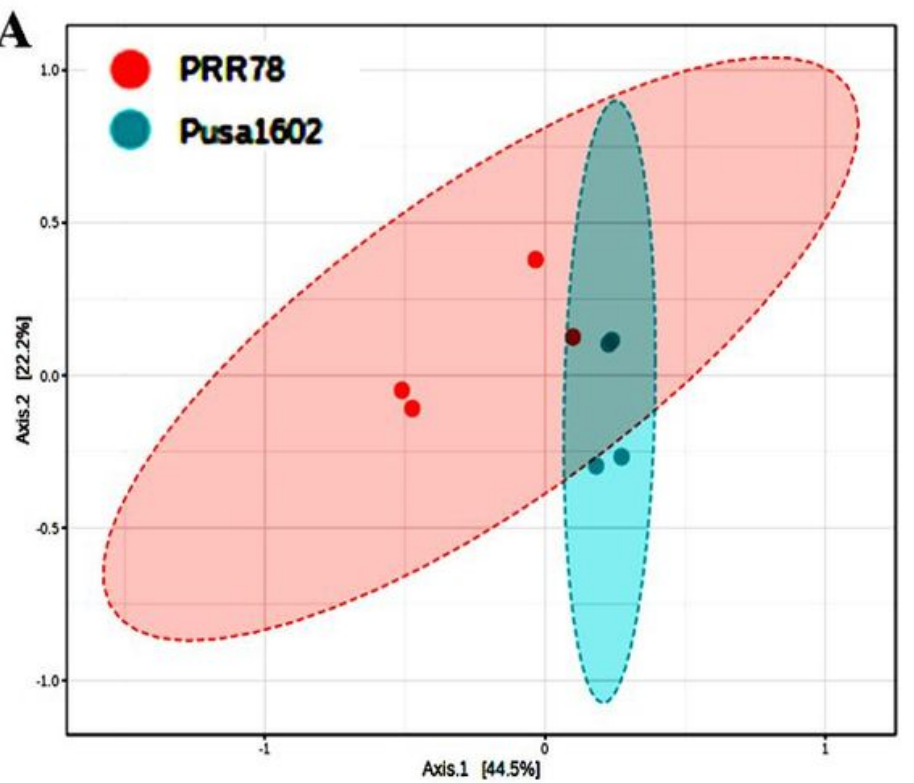

B

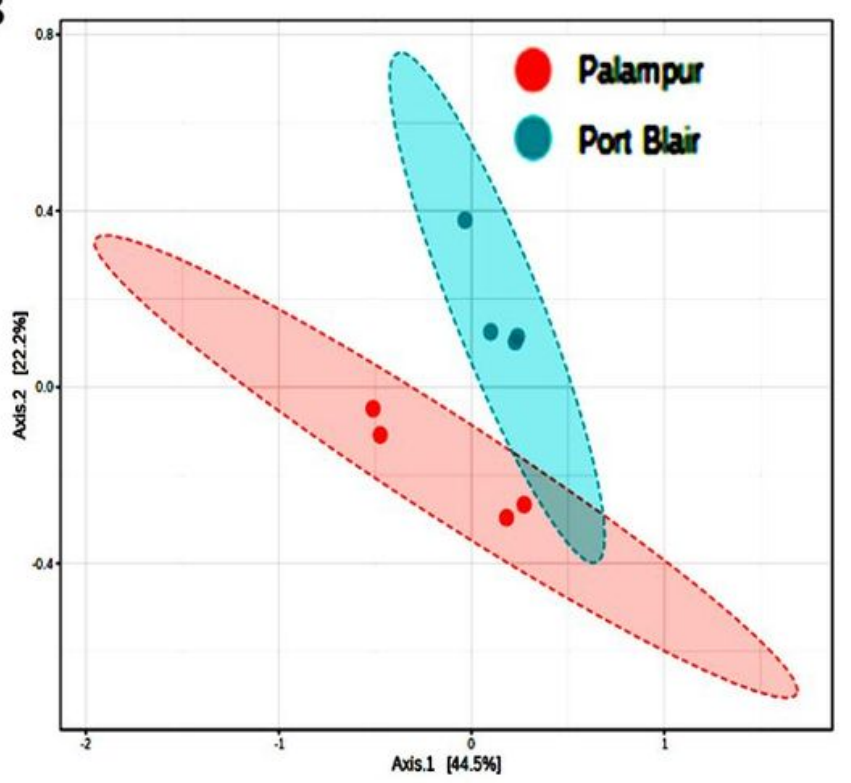

Figure 3 
Principal Coordinate analysis (PCoA) based on Bray-Curtis and ANalysis of SIMilarity (ANOSIM) for rice phyllosphere microbiome between; (A) Two genotypes i.e. PRR 78 and Pusa 1602; (B) Two location i.e. Palampur and Port Blair.

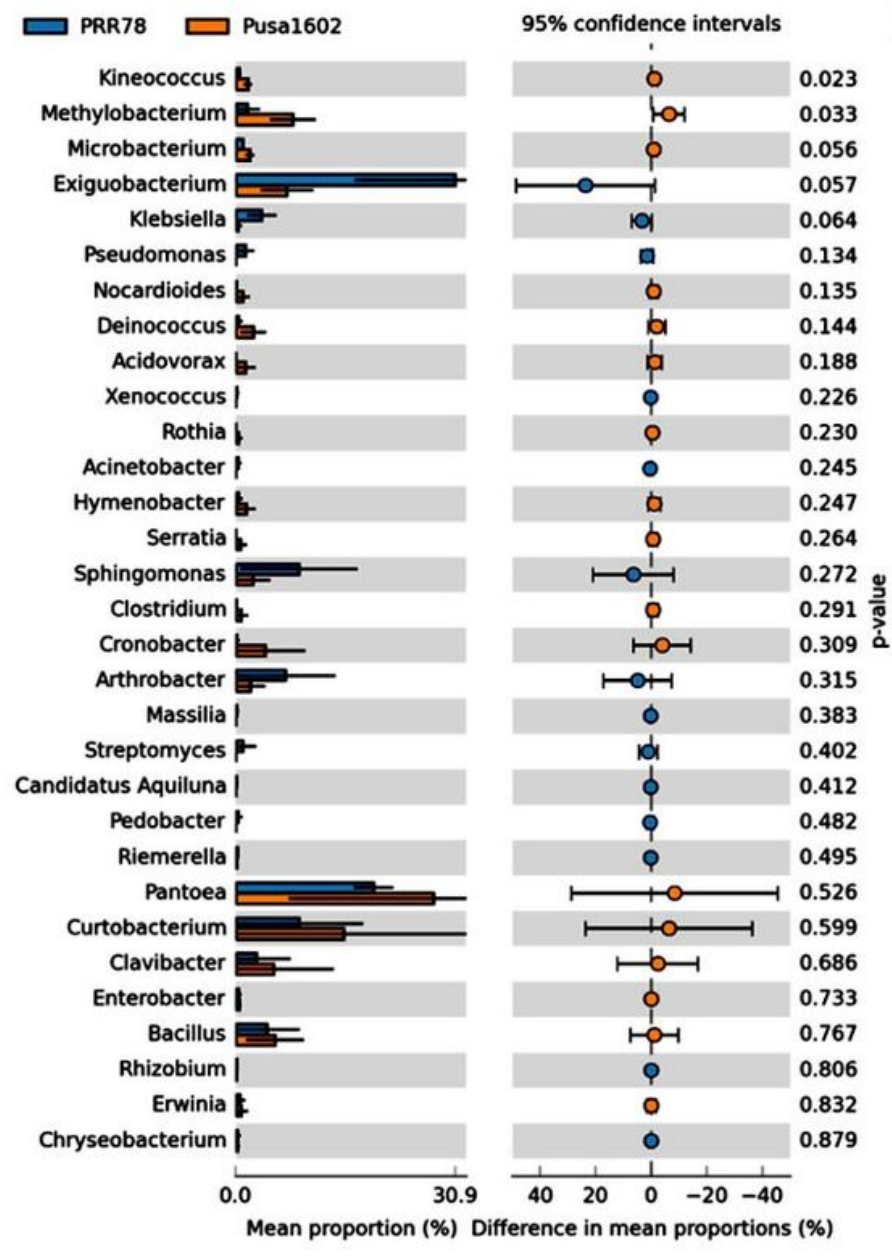

$\square$ Palampur $\square$ Port Blair

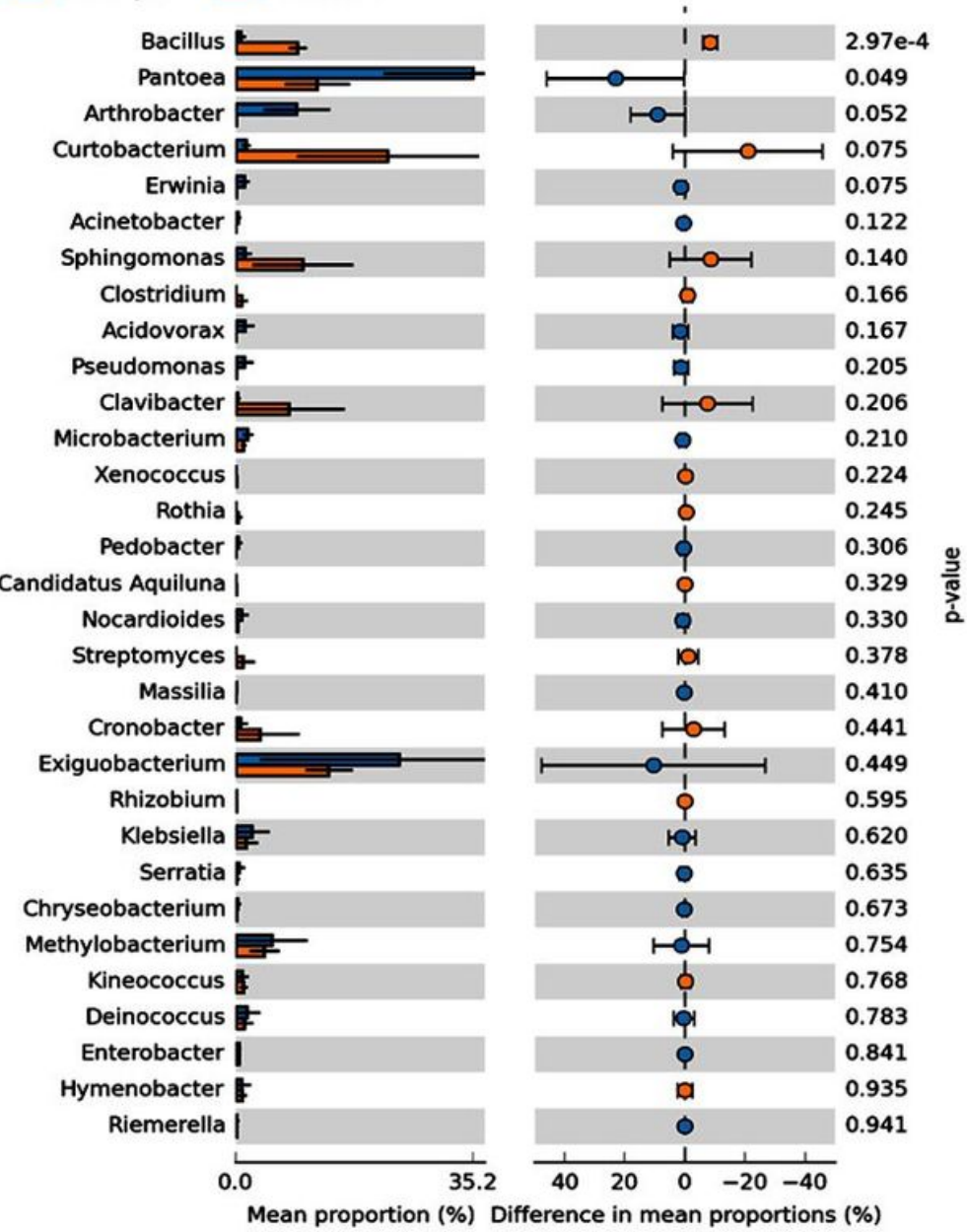

Figure 4

Extended error bar plots for the top 31 microbiota at the genus level (a) Extended error bar plots for the top microbiota at the Genus level for two genotypes.

(b) Extended error bar plots for the top microbiota at the Genus level for two climatic zones. Sorted by significance in ascending order, mean proportion and their differences for phyllosphere microbiota are shown i. Genus Exiguobacterium, Sphingomonas, Klebsiella, Pseudomonas, and Arthrobacter in PRR 78 were significantly higher in abundance than that in Pusa 1602 ii. Genus Methylobacterium, Cronobacter, Pantoea, Curtobacterium, and Clavibacter in Pusa 1602 were significantly higher in abundance than that in PRR 78 iii. Genus Pantoea, Arthrobacter, Exiguobacterium, Klebsiella, and Methylobacterium in the Mountain zone at Palampur were significantly higher in abundance than that in the Island zone at Port Blair iv. Genus Curtobacterium, Bacillus, Sphingomonas, Clavibacter, and Cronobacter in the Island zone at Port Blair were significantly higher in abundance than that in the Mountain zone at Palampur 


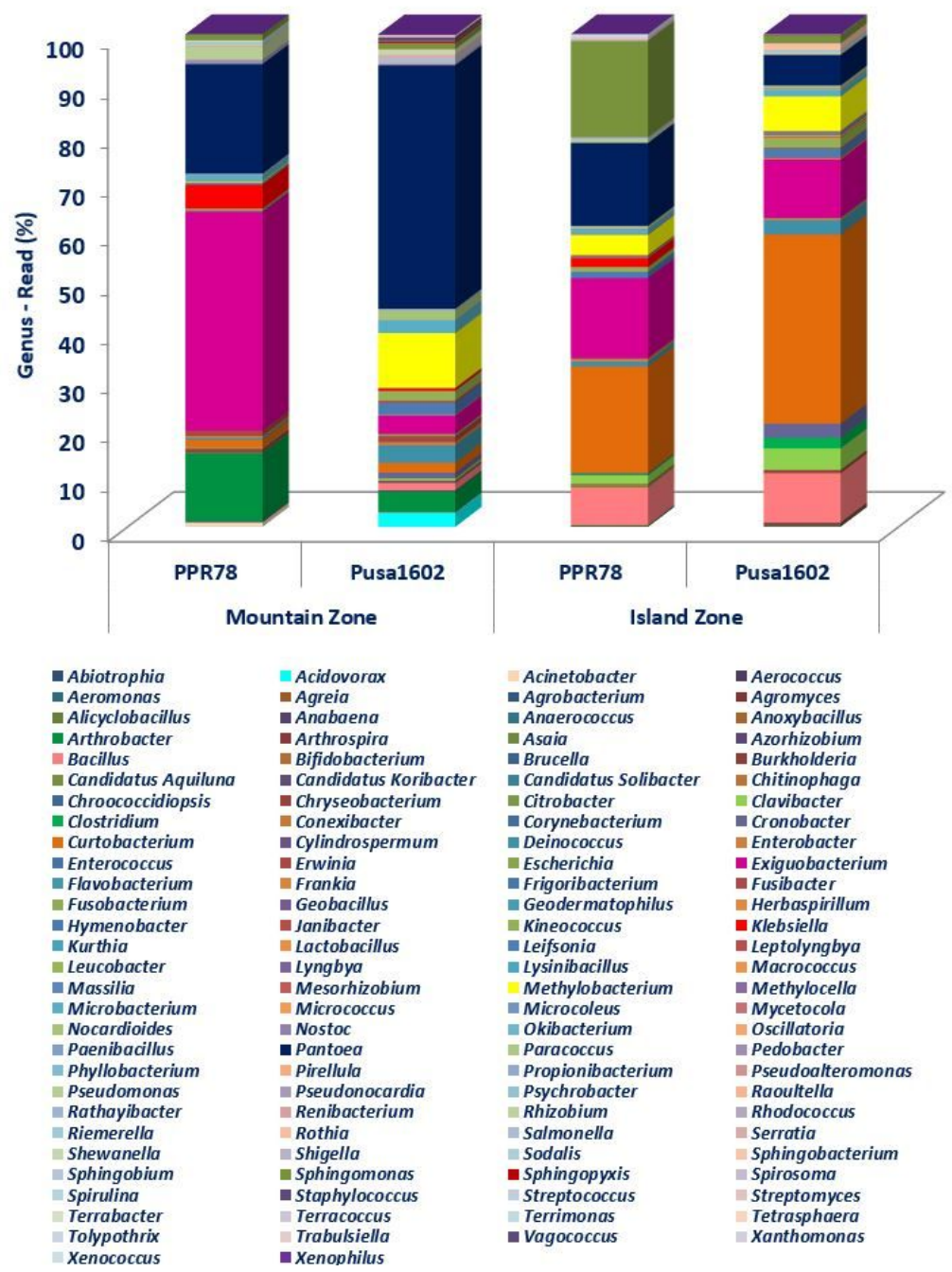

Figure 5

Relative abundance of rice phyllosphere bacterial genera in two contrasting agroclimatic zones of India 

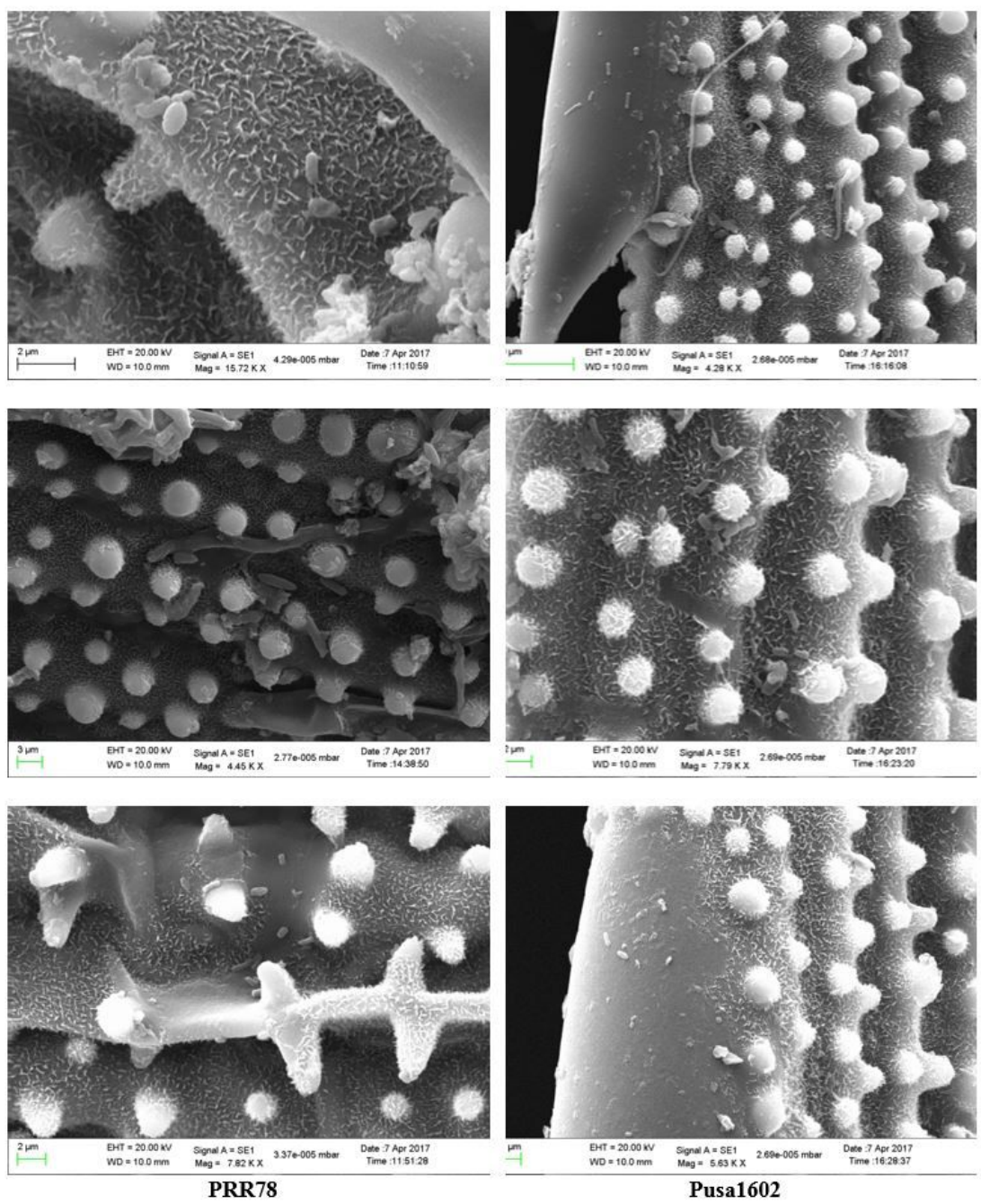

Figure 6

SEM images of rice phyllosphere with bacterial and fungal cells/mycelium on the surface 


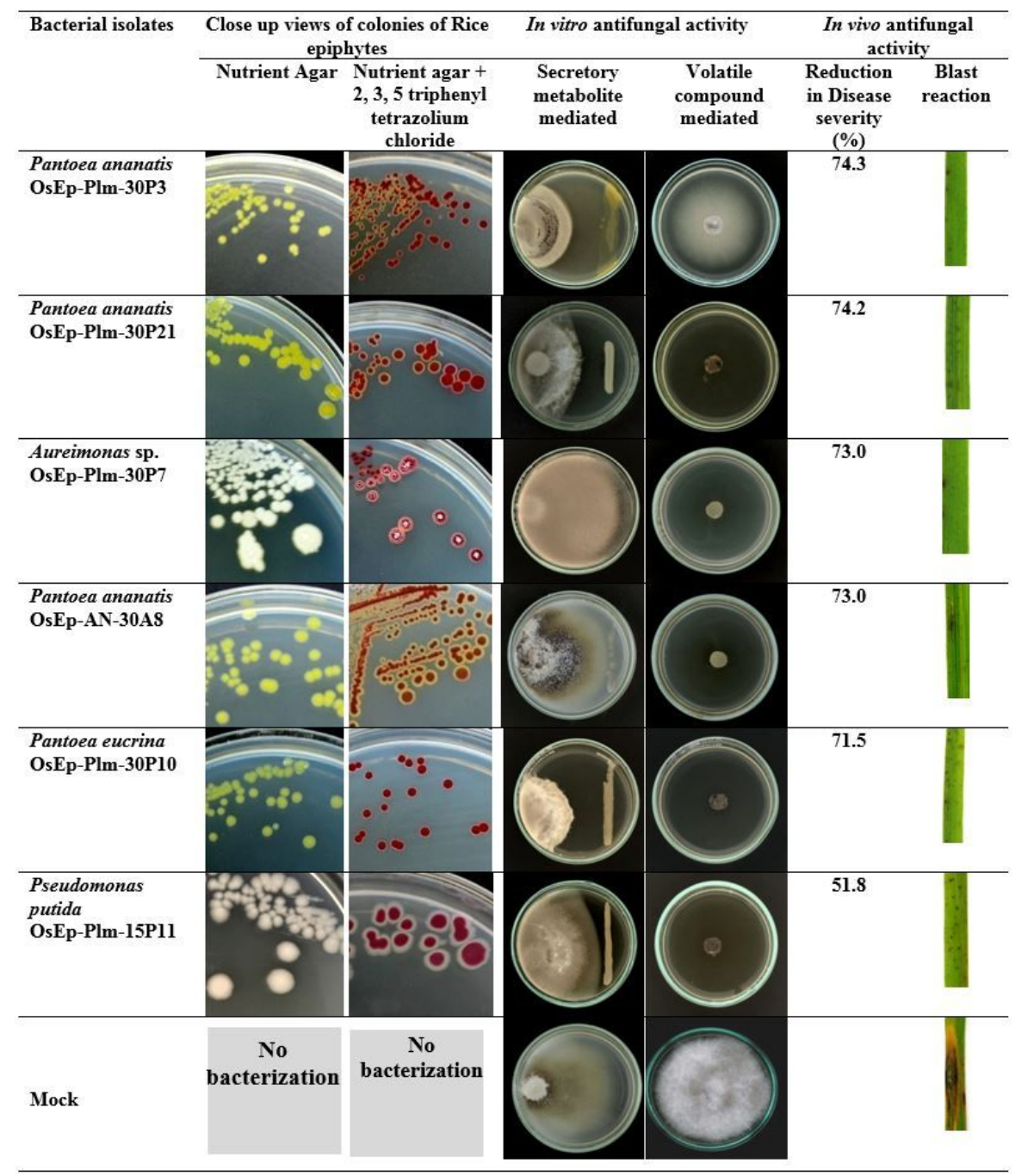

Figure 7

Phyllosphere adapted bacterial isolates found promising for in vitro inhibition of Magnaporthe oryzae and in planta suppression of rice blast disease 

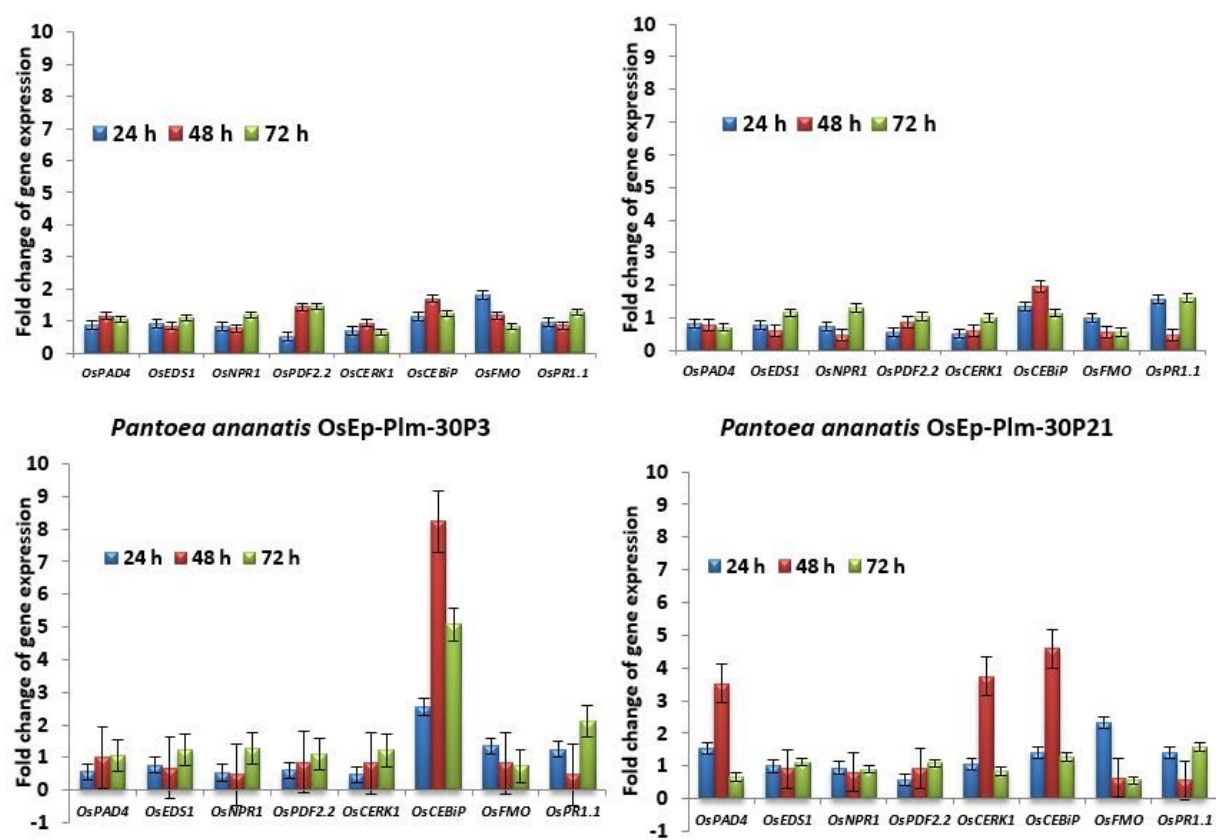

Pantoea ananatis OsEp-PIm-30P21
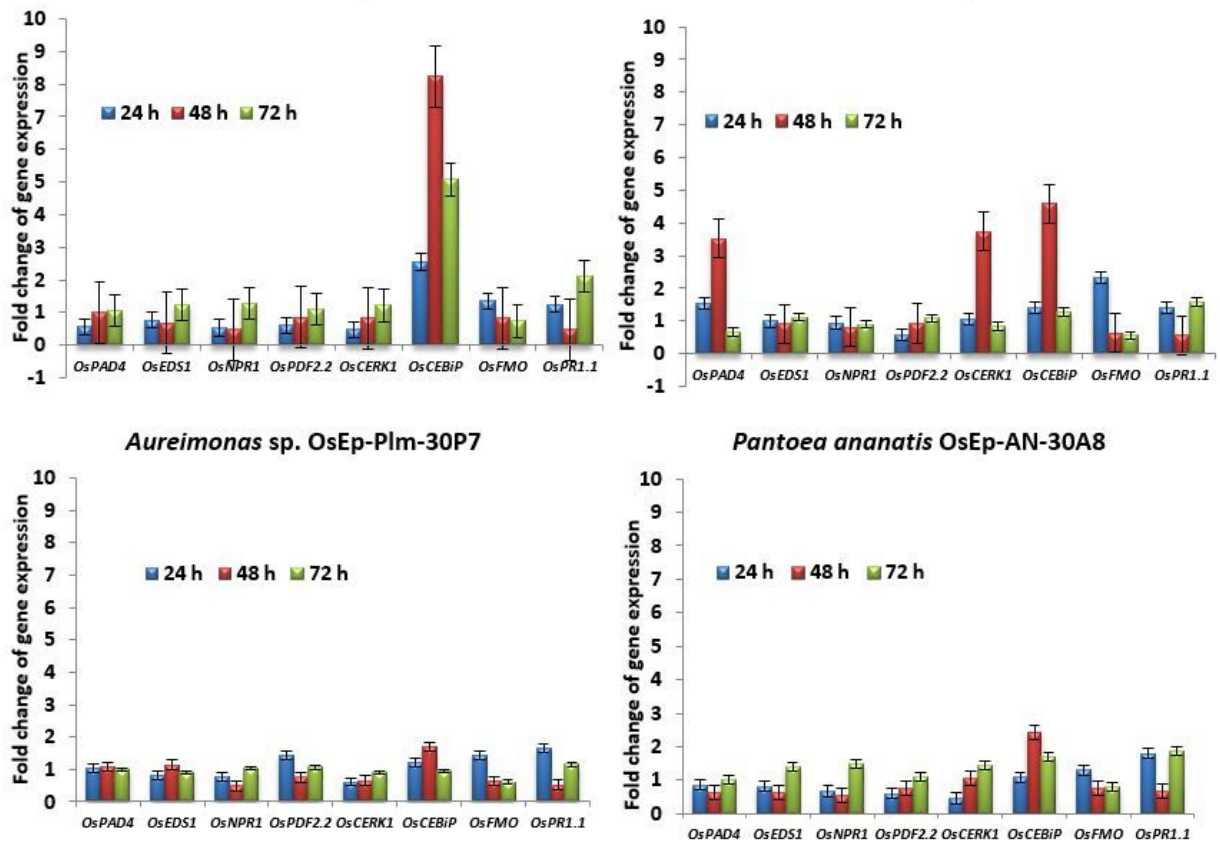

Pantoea eucrina OsEp-PIm-30P10

Pseudomonas putida OsEp-PIm-15P11

Figure 8

qPCR based transcriptional analysis of defense genes expression in rice seedlings upon phyllobacterization

\section{Supplementary Files}

This is a list of supplementary files associated with this preprint. Click to download.

- SupplementaryFiguresMB1.5.docx

- SupplementaryTablesMB1.5.docx 